1 SITDP1 IS REQUIRED TO SPECIFY TAPETUM IDENTITY AND FOR THE

2 REGULATION OF REDOX HOMEOSTASIS IN TOMATO ANTHERS

3 Blanca Salazar-Sarasua, María Jesús López-Martín, Edelín Roque, Rim Hamza, Luis

4 Antonio Cañas, José Pío Beltrán, Concepción Gómez-Mena*

$5 \quad *$ Corresponding author: cgomezm@ibmcp.upv.es

\title{
6 AUTHOR CONTRIBUTIONS
}

7 C G-M designed the research and wrote the grant that founded the project. B S-S, MJ L-

$8 \mathrm{M}, \mathrm{RH}$ and ER performed the experiments. C G-M and B S-S wrote the manuscript. LA

9 C and JP B supervised the study and reviewed the manuscript. All the authors agreed with the final version of the manuscript.

RUNNING TITLE

SITPD1 is required for tapetum development in tomato

One sentence summary

The small protein SITPD1 is required for tapetum formation in tomato, highlighting the role of this tissue in the regulation of redox homeostasis during male gametogenesis.

21 Number of figures: 9

Number of tables: 1

Supporting information: 4 figures, 3 tables (1 of them as an excel file). 


\section{ABSTRACT}

25 The tapetum is a specialized layer of cells within the anther adjacent to the sporogenic tissue. During its short life, it provides nutrients, molecules and materials to the pollen mother cells and microsporocytes being essential during callose degradation and pollen wall formation. However, the acquisition of tapetal cell identity in tomato plants is a process still poorly understood. We report here the identification and characterization of SITPD1 (Solanum lycopersicum TPD1), a gene specifically required for pollen development in tomato plants. Gene editing was used to generate loss-of-function Sltpd1 mutants that showed absence of tapetal tissue. In these plants, sporogenous cells developed but failed to complete meiosis resulting in complete male sterility. Transcriptomic analysis conducted in wild-type and mutant anthers at an early stage revealed the down regulation of a set of genes related to redox homeostasis. Indeed, Sltpd1 anthers showed a reduction of reactive oxygen species (ROS) accumulation at early stages and altered activity of ROS scavenging enzymes. The obtained results highlight the importance of ROS homeostasis in the interaction between the tapetum and the sporogenous tissue in tomato plants.

KEY WORDS: Anther, male sterility, pollen, ROS, tapetum, tomato (Solanum lycopersicum), TPD1 


\section{INTRODUCTION}

Sexual reproduction in both animals and plants requires the formation of haploid gametes in a complex and highly regulated process. Quite unlike animals, in flowering plants the gametes are produced post embryonically within specialized organs, the ovary and the anther. The female gametophyte (embryo sac) is produced from a germline originated in the ovules inside the ovary, while male gametophytes (pollen) originate inside the anther. The formation of gametes in plants occurs late in development and does not depend on meristems but on cell-to-cell communication or tissue interactions.

The anther shows a relatively simple morphological structure and high accessibility being the object of numerous studies on the sexual reproduction of plants. Shortly after anther primordia initiation, several somatic and germinal cells originate. Typically, the primordia contains three cells layers (L1-L3) that will originate the external epidermis, the archesporial cells and the inner vascular and connective tissue (Gómez et al., 2015; Åstrand et al., 2021). Archesporial cells further differentiate into three additional layers of somatic tissue: the endothecium, the middle layer and the tapetum, and a layer of microsporocytes (pollen mother cells, PMC). The tapetum layer, adjacent to the developing microsporocytes has a central role during pollen development and its premature or delayed degradation results in pollen abortion and male sterility (Liu et al., 2018; Bai et al., 2019).

Most of the genetic information on male gametogenesis was obtained in the model plant Arabidopsis thaliana and two monocot crops, rice and maize (Chang et al., 2011; van der Linde \& Walbot, 2019). In Arabidopsis, tapetal cell formation requires the joined action of EMS1/EXS (EXCESS MICROSPOROCYTES1/EXTRA SPOROGENOUS CELLS) a putative Leucin-rich repeat (LRR) receptor kinase (Canales et al., 2002; Zhao et al., 2002) and its ligand the small peptide TPD1 (TAPETUM DETERMINANT1)(Yang et al., 2003; Huang et al., 2016b). In rice, a similar receptor/ligand complex is encoded by the MSP1 (MULTIPLE SPOROCYTE1) and TDL1A genes (Nonomura et al., 2003; Zhao et al., 2008) while in maize a TPD1 homolog, MAC1(MULTIPLE ARCHESPORIAL CELLS1)/MIL2 gene (Hong et al., 2012a; Wang et al., 2012), was identified. Downstream of this complex, several genes such as BRI1 EMS SUPPRESSOR (BES1), DYT1 (DYSFUNCTIONAL TAPETUM1), DEFECTIVE IN TAPETAL DEVELOPMENT AND FUNCTION1 (TDF1) and MYB33/65 are required for early tapetal development and function in Arabidopsis 
(Millar and Gubler, 2005; Zhu et al., 2008; Gu et al., 2014; Chen et al., 2019). At late stages, MALE STERILITY1 (MS1) and AMS regulate pollen formation and maturation (Ito and Shinozaki, 2002; Sorensen et al., 2003). Despite small differences, extensive research in Arabidopsis and rice suggests that the genetic pathway controlling tapetum development is highly conserved in plants (Wilson and Zhang, 2009; Zhang and Yang, 2014; Lei and Liu, 2020).

In tomato, male sterility is a desirable trait to be used in hybrid seed production and cross breeding programs. Over 50 male sterile mutants were isolated more than two decades ago (Gorman and McCormick, 1997) and still only a limited amount of genes involved in male gametogenesis have been identified. Mutations in the tomato SPOROCYTELESS/NOOZLE orthologue prevent the formation of both male and female sporocytes and the plants are fully sterile (Hao et al., 2017; Rojas-Gracia et al., 2017). Downstream of this gene, Ms10 35 gene (DYT1 homolog) encodes a bHLH transcription factor specifically expressed in tapetal tissue and meiocytes (Jeong et al., 2014). Another bHLH protein (Solyc01g081100) has been proposed as the best candidate to encode the tomato Ms32 gene (Liu et al., 2019). Solyc01g081100 gene is a homolog of the Arabidopsis bHLH10/89/90 gene that together with DYT1-MYB35 form a regulatory module to regulate tapetum and pollen development (Cui et al., 2016).

In this work, we identified a gene that is specifically required for the specification of the tapetal cells in tomato. The gene corresponds to the tomato homolog of the TPD1 Arabidopsis gene, and was named SITPD1 (Solanum lycopersicum TPD1). We obtained mutant plants by CRISPR/Cas9 technology that showed a male sterile phenotype associated with the absence of tapetal tissue. We studied the cytological and molecular changes of the anther and in particular the effect in sporogenous cell development in the mutant plants. Our results provide evidence for a regulatory role of the tapetum in the progression of male gametogenesis through the modulation of redox homeostasis.

\section{RESULTS}

\section{Identification of the Solanum lycopersicum SITPD1 gene.}

Following a gene homologue strategy, we selected a gene candidate to be involved in tapetum development in tomato. TPD1 (TAPETUM DETERMINANT1) (Yang et al., 
2003) was used as a bait in the Plant Comparative platform Phytozome (Goodstein et al., 2012) (https://phytozome-next.jgi.doe.gov/) and two homologous were identified (Solyc03g097530 and Solyc11g012650). The expression of these genes was analyzed in vegetative tissues (leaves) and flower buds using qPCR. The results showed that Solyc11g012650 was preferentially expressed in leaves while Solyc03g097530 was expressed in developing flowers, reaching the highest level in flower at anthesis (Figure S1). Phylogenetic analyses were performed using a list of homologue genes from different plant species obtained in a BLAST search using TPD1 gene (At4g24972) as a bait. These sequences also included the Arabidopsis closest homolog At1g32583 and the rice orthologue OsTDL1A (Zhao et al., 2008). In the phylogenetic tree, Solyc03g097530 grouped with TPD1 and related TPD1-like homologues from Solanaceae (Figure 1A).

Solyc03g097530 protein sequence (176aa) was aligned with Arabidopsis TPD1 and two protein homologs functionally characterized: TDL1A from rice (Zhao et al, 2008) and MAC1 from maize (Wang et al., 2012). The proteins showed high amino acid identity mainly in the C-terminal region with six highly conserved cysteine residues and a putative dibasic cleavage site (Figure 1B). In addition, SlTPD1 protein and homologs contain a predicted signal peptide at their N-terminal regions (Figure 1B; underlined). The subcellular location of the protein was determined by fusing the Yellow Fluorescent protein (YFP) to the C terminal end of SITPD1 and transiently expressed in Nicotiana benthamiana leaves. The control protein (35S:GFP) exhibited both cytoplasmic and nuclear localization (Figure 1C) while SITPD1-YFP protein was localized in proximity of the plasma membrane where it formed small dots, and in the cytosol as large aggregates (Figure 1C). This result suggests that SITPD1 protein could be secreted to the extracellular space.

Gene orthology and local microsynteny or collinearity was inferred by in silico analyses. The use of the Gene Orthology View in the PLAZA platform (Van Bel et al., 2018) confirmed that Solyc03g097530 is the best orthologous candidate for TPD1 in tomato (Figure S2A). We then looked for microsynteny in the flanking regions where the two genes are located and found collinearity between these two regions (Figure S2B). Therefore, we considered Solyc03g097530 the strongest candidate to be the TPD1 orthologous in tomato and renamed it SITPD1 (Solanum lycopersicum TPD1). we designed an experiment to complement a loss-of-function tpd1 mutant. We used a 
mutant line (N843482, tpd1 mutant) that contains a T-DNA insertion in the TPD1 gene. Mutant plants were indistinguishable from the wild type except for the anthers that did not produce pollen grains (Figure 1C). To complement the mutant phenotype, we generated a genetic construct by fusing $2.7 \mathrm{~kb}$ of the promoter region of Arabidopsis TPD1 and the coding sequence of SITPD1 that was used to genetically transform heterozygous tpd1 plants. We obtained 32 independent transformants and four of them were homozygous for the mutation. These four plants produced viable pollen (Figure 1D) and seeds and therefore, were fertile, demonstrating the ability of SITPD1 protein to replace TPD1 function.

\section{Expression of SITPD1 during tomato plant development}

The expression of SITPD1 was analyzed in different plant tissues including seedlings (apical and basal regions), leaves and developing flowers using qPCR. The gene was expressed in all the tissues analyzed reaching the highest level in flowers at anthesis (Figure 2A). The spatial and temporal pattern of expression of SITPD1 was evaluated during flower development using in situ hybridization (Figure 2B-G). SITPD1 RNA was not detectable in inflorescence meristems and flower buds before anther primordium differentiated (Figure 2B). Expression was first detected at floral stage 6 at the internal layers of the developing anther that will generate the sporogenous tissue (Figure 2C, D). Later, at the tetrad stage, SITPD1 transcript was localized at the tapetum and the microspores still surrounded by the callose wall. The expression of the gene continues during the following floral stages in the tapetal cells that gradually disintegrated and in the pollen grains (Figure 2E-G). On the ovary, we detected transient expression in ovule primordia of flower at stage 8 (Figure S3).

\section{Sltpd1 mutants are male sterile and developed parthenocarpic fruits}

To study the function of SITPD1, tomato lines with mutations targeted to the third exon were generated using CRISPR/Cas9 (Figure 3A). Among the T0 generation, we selected six diploid plants that showed percentages of edition over eighty and that mostly contained biallelic mutations (Figure S4A). All the plants showed complete male sterility and developed seedless (parthenocarpic) fruits. Histological sections of the mature anthers revealed collapsed locules containing a dense debris but they did not contain viable pollen (Figure S4B). In these plants, we observed a strong correlation between male sterility and the development of parthenocarpic fruits (Figure S4C). 
$172 \quad F_{2}$ plants were obtained after pollination with wild-type pollen and stable singlemutation lines were obtained. Two mutant lines (Sltpd1 ${ }^{\text {Del5 }}$ and Sltpd1 ${ }^{\text {Del2 }}$ ) containing deletions of 2 and 5 nucleotides respectively were chosen for further analysis (Figure 3A). Mutant plants did not show morphological defects during vegetative development. However, after flower opening, we observed a small reduction in the stamen length, absence of pollen and slight protrusion of the pistil (Figure 3A). For many crops, including tomato, the production of hybrids is an efficient way to increase plant production and improve their resistant to diseases and its performance under suboptimal environmental conditions (Labroo et al., 2021). Male-sterile tomato plants with protruding stiles, such as Sltpd1 mutants, could be valuable parental lines for hybrid seed production. Despite male sterility, Sltpd1 mutant plants produced seedless fruits that were smaller than those of wild-type plants with a decrease of about $70 \%$ in weight (Figure 3C). Fruit shape, quantified as a width/height ratio, was not altered in Sltpd1 mutants (Figure 3C). When fertilized with wild-type pollen, the plants developed seeded fruits of a normal size.

\section{Male gametogenesis fails to be completed in Sltpd1 mutants}

To elucidate the biological function of SITPD1 during male gametogenesis, we compared the development of anthers from the wild type and Sltpd1 mutants. In wildtype tomato anthers, cells from the L2 layer differentiate into archesporial cells that undergo periclinal divisions (parallel to the epidermis) (Figure 4A). In Sltpd1 mutant, anther development was slightly different to the wild type showing cells with squared rather than rectangular shape and reduced number of periclinal divisions (Figure 4D). From stage 8, we observed clear differences between the two genotypes. While epidermis, endothecium and middle cell layers were formed, tapetum was not present in the mutant and sporogenous cells seemed more abundant and disorganized compared to the wild type (Figure 4E). At stage 10, wild-type microsporocytes completed meiosis and formed tetrads surrounded by callose and separated from the adjacent cell layers (Figure 4C). Eventually, callose was degraded, releasing the microspores that continued to develop into mature pollen grains during floral stages 12 to 16 (Figure 4G-I). Simultaneously, the tapetum started to degrade and was not visible by stage 16 (Figure 4I). In the mutant anthers, microsporogenous cells continued to divide and enlarged in size (Figure 4F). After extra rounds of divisions, the cells occupied the complete cavity of the locule (Figure $\mathbf{4 J}$ ). Cell counting showed that by floral stage 8 the number of 
sporogenous cells in Sltpd1 anther locules roughly doubled that of wild-type anthers (24.0 \pm 5.8 versus $49.0 \pm 4.7$ cells/locule section). At stage 10 , sporogenous cell number further increased (66.1 \pm 11.3 cells/locule section) and cells seemed to have initiated meiosis but failed to complete it (Figure $\mathbf{4 J}$ ). Finally, cells degenerated causing the collapse of the anther locules and the deposition of a dense cell debris (Figure $\mathbf{4 L}, \mathbf{L}$ ).

We performed in situ hybridization essays using probes for the tapetum-specific TomA5B (Solyc01g086830) gene (Aguirre and Smith, 1993) and for the tomato homologue (Solyc04g008070) of the meiosis marker SOLO DANCER (SDS) gene (Azumi et al., 2002). In the wild type anther, TomA5B probe strongly hybridized with the tapetal cells at floral stages 8 and 10 (Figure 5A, B). The signal decreased dramatically by stage 12 when tapetum degeneration starts (Figure 5A). In the Sltpd1 mutant anthers no signal was obtained in any of the floral stages analyzed (Figure 5DF) confirming the complete absence of tapetum in the mutant plants. In the case of SISDS probe, the hybridization signal was first observed in the wild type at floral stage 8 overlapping with meiosis initiation (Figure 5B). A similar result was obtained in the mutant anther detecting the expression of the gene at floral stage 8 (Figure 5B). These results indicate that meiosis was initiated in the mutant anthers although it failed to progress to the tetrad stage.

Callose deposition occurs around the sporogenous cells predating meiosis initiation and later between meiotic products (Jaffri and MacAlister, 2021). After meiosis completion, callose is quickly degraded after the release of callases (ß1-3 glucanases) by the tapetum. Using aniline blue staining the pattern of callose deposition and degradation was analyze in the mutant plants. In wild type anthers, the deposition of callose appears as an intense florescence signal around the tetrads that quickly disappears at the termination of meiosis (Figure $5 \mathbf{C}$ ). In the mutant plants, the accumulation of callose was observed as a diffuse signal surrounding the sporogenous cells and the fluorescence signal persisted in time until the collapse of the anther locule (Figure 5C).

\section{Identification of global transcriptional changes associated to SITPD1 loss-of- function.}

To identify molecular and cellular components downstream of SITPD1 action, RNAseq analyses were performed using anthers from floral stage 8 (meiotic stage). Differential expressed genes (DEG) were selected using a Q-value $>0.1$ and $p$-value $>0.05$. From the 
237 selected genes (801), 519 correspond to down-regulated genes and 282 to up-regulated genes (Figure 6A and Table S1).

At early floral stage 8, Gene Onthology (GO) analyses revealed enrichment in genes related to pollen and tapetum development (five out thirteen categories that correspond to 49 genes; Figure 6B and Table S1). Among these genes, homologs to DYT1, AMS, MYB35 and bHLH91 showed strong downregulation (Table 1). Accordingly, in Arabidopsis DYT1 is required to activate the expression of bHLH010/bHLH089/bHLH091 genes which in turn facilitate DYT1 nuclear location and promote MYB35 expression (Cui et al., 2016). In addition, we detected strong downregulation of genes required during late stages of pollen development including a polygalacturonase homolog of the Arabidopsis QRT3 gene involved in microspore separation (Rhee et al., 2003) and a fatty acid-CoA reductase (Table 1).

When looking at signaling pathways, an important group of redox related genes was observed grouped under "cellular response to hydrogen peroxide" and "defense response”. A specific expression heat-map analysis of redox-related genes revealed differential expression of seventy genes, of which fifty-three were downregulated and seventeen were upregulated (Figure 6C and Table S1). Among the downregulated genes (Table 1), we detected two Respiratory burst oxidase homolog (Rboh) genes (also known as NADPH oxidases), key enzymes that catalyze the formation of ROS in plants and a glutaredoxin (GRX) that shows homology with the MIL1 gene from rice involved in microspore development (Hong et al., 2012b). Moreover, nine peroxidases are downregulated in the mutant anthers including homologues of the previously characterized PRX9 and PRX40 involved in pollen development in Arabidopsis (Jacobowitz et al., 2019). Peroxidases are multifunctional proteins that catalyze the oxidation of a variety of substrates by $\mathrm{H}_{2} \mathrm{O}_{2}$ and act as efficient components of the antioxidative system controlling ROS.

We analyzed the contribution of the genes involved in redox homeostasis to the development of the tomato anther. From the list of DEGs a subset of key ROS-related genes was selected, and its expression level were checked in anthers from different developmental stages (St6 to St20). The expression of two tomato $R B O H$ genes (SIRbohA/Solyc01g099620 and SIRbohE/ Solyc06g075570) was analyzed by qPCR.

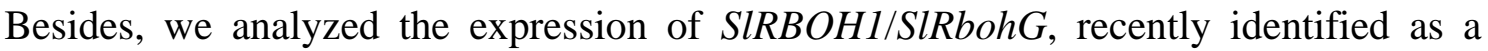
brassinosteroid (BR)-regulated gene involved in tapetal cell degeneration and pollen 
270 development (Yan et al., 2020). In Sltpd1 mutant anthers we detected an important

271 reduction in the expression level of SIRbohA and SIRbohE at early stages of anther

272 development (Figure 7A, B). The expression levels of SIRBOH1/ SlRbohG did not significantly change during the floral stages analyzed (Figure 7C).

274 The expression of the glutaredoxin-C9-like gene SlGRXC9/Solyc08g036570 was 275 analyzed and high levels of expression were detected in the wild type at the earliest stages analyzed (floral stage 6 and 8), while in the mutant samples the expression level was greatly reduced (Figure 7A). The expression of two TGA-like transcription factors (Solyc06g074320/SITGA9 and Solyc10g078670/SITGA10), downregulated in the RNAseq, were also analyzed. Quantitative qPCR experiments indicated that while SITGA9 showed reduced expression in the mutant in floral stages 8, 14 and 15, SITGA10 expression was strongly reduced in the mutant anthers from floral stage 8 and this low level persisted until floral stage16 (Figure 7B, C). In Arabidopsis, ROXY1/ROXY2 glutaredoxins interact with TGA9/TGA10 transcription factors in the regulation of anther development (Murmu et al., 2010).

Globally, the expression analyses suggested that the absence of SITPD1 and its downstream genetic network prevent the activation of the genes involved in the modulation of ROS levels, especially during early stages of anther development.

ROS accumulation is lower in Sltpd1 anthers than in the wild type at early developmental stages

The presence of reactive oxidative species was tested in the anthers of wild type and Sltpd1 mutant plants. We analyzed and quantified the presence of superoxide anion $\left(\mathrm{O}_{2}{ }^{-}\right)$and $\mathrm{H}_{2} \mathrm{O}_{2}$, considered the major ROS forms in plant cells (Huang et al., 2019), using 3-3'-diaminobenzidine (DAB) and nitroblue tetrazolium (NBT) staining, respectively. Quantification of NBT-staining of the anthers, a proxy for superoxide anion presence, detected the highest levels at floral stages 8 and 10 but no differences were observed between wild-type and mutant anthers (Figure 7A). DAB quantification showed that in both wild-type and mutant anthers, the level of $\mathrm{H}_{2} \mathrm{O}_{2}$ is higher at floral stage 8 and then decreases progressively. Interestingly, at early stages (St8 and St10) the level of $\mathrm{H}_{2} \mathrm{O}_{2}$ was significantly lower in Sltpd1 than in the wild type (Figure 7B). These results suggest that a critical $\mathrm{H}_{2} \mathrm{O}_{2}$ threshold should be reached during early stages of anther development concurring with the meiotic stage. 
In plants, the maintenance of ROS levels also relies on the action of non-enzymatic and enzymatic scavenging mechanisms. This last mechanism include enzymes such as, superoxide dismutase (SOD), catalase (CAT) and peroxidases (PRX) (Huang et al., 2019). To study the functionality of these enzymatic scavenging mechanism in the flowers of the mutant plants, we measured SOD and PRX activities. Compared to the wild type, SOD activity showed significant reduction in the mutant plants at floral stages 6 (premeiotic), 16 (pollen mitosis) and 20 (anthesis) (Figure 8C). Remarkably, PRX activity was much reduced in Sltpd1 mutant anthers (Figure 8D) in agreement with the global downregulation of peroxidases shown in the RNA-seq experiment (Table 1).

\section{DISCUSSION}

\section{SITPD1 is required for tapetum formation and pollen development in tomato.}

The stamens are the male reproductive organs of angiosperms and the place where the pollen is produced within the flower. The different tissues that compose anthers sequentially develop from the anther primordia suggesting that cell-to-cell communication is critical to coordinate growth and development (van der Linde and Walbot, 2019). The tapetum is the limiting tissue between the somatic and germinal cells and it is in a dynamic state during its short life period facilitating the pass of nutrients and molecules to the sporogenous cells and microspores (Pacini and Cresti, 1978).

In this study, we evince the pivotal role of the tapetal tissue during pollen development throughout the isolation and characterization of the SITPD1 gene. SITPD1 shows homology with the TPD1 protein from Arabidopsis and, when transformed into the tpd1 mutant, it was sufficient to complement the fertility defects. In addition, protein sequence alignments showed strong domain conservation also with the monocot proteins TDL1A/MIL2 and MAC1 from rice and maize. Therefore, SITPD1 is the ortholog of the TPD1, MAC1 and TDL1A/MIL2 genes and the first gene ortholog identified in a fleshy fruit plant. On the other hand, although in tomato the putative receptor for SITPD1 protein has not been yet identified, our data suggest the conservation of the receptor/ligand module also in tomato plants.

In Arabidopsis, mutant plants in either EMS1 (TPD1 receptor) or TPD1 genes share a phenotype, the lack of tapetum and the production of extra sporocytes at the expense of tapetal cells (Zhao et al., 2002; Yang et al., 2003). We detected the expression of 
SITPD1 by in situ hybridization on the anther wall early in development until late stages where it appeared associated to the tapetum and microsporocytes. In this aspect, SITPD1 slightly differs from TPD1 that is preferentially expressed in microsporocytes while EMS is predominantly expressed in tapetum (Zhao et al. 2002; Yang et al. 2003). In maize, MAC1 is expressed early in anther ontogeny where it suppresses archesporial cell proliferation, suggesting that cell position, rather than lineage regulates cell fate determination during anther development (Wang et al., 2012). This hypothesis is in agreement with the phenotype of Sltpd1 mutants that showed defects in the shape and pattern of division of the archesporial cells. It has been shown that ectopic expression of TPD1 activates cell division possibly by regulating the expression of cell-cycle genes (Huang et al., 2016a). Taken together, we propose a dual role for SITPD1 in the control of archesporial cell divisions and the determination of tapetal cell identity in tomato plants.

Most TPD1 homologs are expressed in different tissues outside the anther including leaves, roots, seedlings (Yang et al., 2003; Hong et al., 2012a; Wang et al., 2012) and ovules (Yang et al., 2005; Wang et al., 2012). At present, a possible role of these proteins during vegetative development remains elusive. However, in monocots TPD1 orthologs have been reported to control megaspore mother cell proliferation during ovule development (Sheridan et al., 1996; Zhao et al., 2008). Using in situ hybridization, the expression of SITPD1 was detected in anthers and the developing ovules. Sltpd1 mutant plants did not show obvious defects in ovule development and flowers formed normal seeded fruits when pollinated with wild-type pollen. A peculiar and distinctive phenotype of the tomato Sltpd1 mutants is the formation of seedless fruits (parthenocarpic). Parthenocarpy, the formation of fruits in the absence of pollination and fertilization, is often the consequence of the precocious activation of molecular events normally triggered by these processes (Molesini et al., 2020). Also, it could be achieved by external applications of different hormones or growth regulators (Vivian-Smith and Koltunow, 1999). In tomato plants, several reports suggest a role for developing stamens or male gametophytes in the repression of ovary growth (Medina et al., 2013; Hao et al., 2017; Rojas-Gracia et al., 2017; Okabe et al., 2019). Mutations in SITPD1 caused complete male sterility and the production of small parthenocarpic fruits. This phenotype could support this repressive effect exerted by male gametogenesis progression. Alternatively, the abnormal progression of male 
gametogenesis could result in the production of signaling molecules that indirectly activate premature ovary growth. In this regard, antisense plants targeting SIRBOHB/SIWfi1 a tomato gene involved in the generation of ROS, show several developmental defects including parthenocarpic fruit development (Sagi et al., 2004).

\section{SITPD1 and the control of redox homeostasis during pollen development}

372 Overlapping with the genetic network controlling anther development, additional factors and signalling molecules participate in the communication between the somatic and sporogenous tissues. These factors include hormones, secreted proteins, miRNAs and cellular redox state (Dukowic-Schulze and van der Linde, 2021). For instance, the analysis of gibberellin (GA) deficient mutants suggest that the primary site of hormone action are tapetal cells and low GA levels have an indirect effect on the formation of functional pollen grains (Aya et al., 2009). Several lines of evidence support that cellular redox state is an important morphogenetic factor controlling cell differentiation and proliferation during anther development (Yu and Zhang, 2019).

Interestingly, while high concentration of reactive oxygen species (ROS) cause irreversible DNA damage and cell death, at low levels ROS act as signalling molecules regulating cell division and cell fate (Kelliher \& Walbot, 2012; Yang et al., 2018). The results presented in this study show that the absence of tapetal tissue in Sltpd1 mutants have a huge impact in the transcription of genes involved in redox homeostasis in the anther at early stages. Moreover, a reduction in ROS levels seem to be associated with the failure of pollen mother cells to progress into meiosis. In agreement with this observation, pioneering work in maize showed that hypoxia triggers meiotic fate acquisition acting as a positional cue for germ cell production (Kelliher and Walbot, 2012).

Besides the production of ROS as an end product of several metabolic processes, a specific enzymatic machinery is in charge of maintaining redox homeostasis in plants. ROS production relays on $R B O H$ genes also known as NADPH oxidases, which catalyze the generation of superoxide radicals. Enzymatic scavenging mechanism involve SOD, CAT and peroxidases, although peroxidases can act as both ROSgenerating and ROS-processing components (Mittler, 2017). Cellular changes of ROS 
tapetum and the genetic interference with the temporal ROS pattern resulted in altered tapetal PCD and male sterility (Xie et al., 2014). In addition, PRX9 and PRX40 are extensin peroxidases specifically expressed in the tapetum that act as scavenging molecules contributing to tapetal cell wall integrity (Jacobowitz et al., 2019). ROS signalling include glutaredoxins (GRXs) that act as sensors of the redox status, altering signal transduction pathways that result in biological responses (Song et al., 2002). Studies in Arabidopsis, rice and maize highlighted the importance of GRXs in the formation of the anther and the differentiation of microsporocytes (Xing and Zachgo, 2008; Hong et al., 2012b; Kelliher and Walbot, 2012). In rice, a mutation in the antherspecific glutaredoxin MICROSPORELESS1 (MIL1) prevent the completion of the meiosis during male gametogenesis. MIL1 encodes a CC-type glutaredoxin that specifically interact with TGA transcription factors (Hong et al., 2012b). In Arabidopsis, ROXY1 and ROXY2 encode also CC-type glutaredoxins and are required for the formation of the adaxial anther lobe possibly with other GRXs or redox regulators. ROXY1 and ROXY2 proteins are able to interact with the TGA transcription factors TGA9 and TGA10 in tobacco leaves (Xing and Zachgo, 2008). These authors suggest that this interaction results in the modification of TGA9/10 and its activation as a transcriptional factor (Murmu et al., 2010). A similar genetic network to the one described in rice and Arabidopsis should operate in tomato anthers where ROS produced in the tapetal cells orchestrate anther wall development and pollen mother cells progression into meiosis. Using a tomato mutant lacking the tapetum, we identified several elements of this network that were included in the proposed working model (Figure 9). ROS produced by RBOHs (SIRbohB and SIRbohE) and peroxidases results in the accumulation of $\mathrm{H}_{2} \mathrm{O}_{2}$ in tapetal tissue. Glutaredoxins, including SIGRXC9, could target TGA transcription factors (SITGA9 and SITGA10) for activation, regulating then the expression of a set of genes required for further stages of pollen and anther development. This genetic network is severely affected by the absence of SITPD1 and the concomitant loss of the tapetal tissues, at early stages of anther formation.

In the present study, we identified and characterized the tomato gene SITPD1 that has a central role in pollen formation. Using CRISPR/Cas9 technology, we generated male sterile tomato plants that specifically lack tapetal tissue to gain insight into the genetic network and molecular signals regulating pollen formation in this species. Based on the 
431 obtained information, a working model is proposed highlighting the role of ROS

432 production and signalling during early stages of pollen development in tomato plants.

MATERIALS AND METHODS

\section{Plant material and growth conditions}

Tomato (Solanum lycopersicum L.) seeds from cultivar Moneymaker were grown in a greenhouse in pots with a 2:1:1 mixture of peat:vermiculite:perlite with a temperature regime of $25-30^{\circ} \mathrm{C}$ day and $18-20{ }^{\circ} \mathrm{C}$ night. Natural light was supplemented with lamps to obtain a 16h light/8 h night photoperiod. Flower samples were collected at different developmental stages according to bud size (Brukhin et al., 2003). In this study, 8 floral stages were analyzed that correspond to the following sizes: St6 $(0.3 \mathrm{~cm})$, St8 $(0.4 \mathrm{~cm}$; meiotic), St10 (0.5 cm; tetrad of microspores), St12 (0.6 cm), St14 (0.7 cm), St16 (0.8 cm; pollen mitosis), St18 $(0.9 \mathrm{~cm})$ and St20 (1 cm; anthesis). For the characterization of tomato fruits, size and weight of at least thirty fruits from the different genotypes were analyzed when fully ripe.

Arabidopsis thaliana Columbia (Col) plants were used as the wild-type genotype. The tpd1 mutant corresponds to the T-DNA insertion line N843482 (SAIL_1174_B09) obtained from Nottingham Arabidopsis Stock Centre (NASC). The line was genotyped using the T-DNA specific primer LBb1 and the gene specific primer pair TPD1LP1/TPD1-LP2 that amplifies 427 bp from the TPD1 gene (Supplementary Table S2). Arabidopsis plants were grown in seed pots in a growth chamber with a 2:1:1 mixture of peat:vermiculite:peat at $21^{\circ} \mathrm{C}$ under long day conditions (16h light/8 h dark) and irrigated with Hoagland's solution.

\section{Phylogenetic analysis}

455 The phylogenetic tree was inferred by the neighbor-joining method using Poisson456 corrected amino acid distances. A total of 1000 bootstrap pseudo-replicates were used to 457 estimate reliability of internal nodes. Tree inference was performed using MEGA 458 version 6 (Tamura et al., 2013). The dataset comprised 18 TPD1-like genes from 459 different plant species, obtained from GenBank database (Table S1).

\section{Plasmid assembly}


461 Construct for the complementation of the Arabidopsis tpd1-2 mutant: A fragment of 2.7

$462 \mathrm{~kb}$ from the TPD1 promoter (5' region of the gene) was fused to the coding sequence of 463 the tomato SITPD1 gene. First, both fragments were independently amplified by PCR 464 and cloned into the intermediate vectors pENTRY 5' TOPO and pCR8 (Invitrogen), 465 respectively. Second, a multisite gateway recombination reaction was performed to 466 introduce both sequences into the binary destination vector pK7m24GW,3 467 (https//gateway.psb.ugent.be) to obtain the final construct pAtTPD1::SITPD1.

468 Design of gRNA and CRISPR/Cas9 construct for SITPD1 gene editing: For the design 469 of optimal gRNAs, the target site was selected using the Breaking-Cas design tool 470 (Oliveros et al., 2016). This tool is freely available on line 471 (https://bioinfogp.cnb.csic.es/tools/breakingcas). CRISPR/Cas9 plasmid assembly was 472 performed using the Golden Braid (GB) modular framework and tools 473 (http://www.gbcloning.upv.es). First, a single gRNA sequence was obtained by annealing of complementary primers and then assembled with GB1001 (U626 promoter) and GB0645 (scaffold RNA) parts into the destination vector pDGB3 $\alpha 1$. In successive multipartite GB reaction, this first module was assembled together with the GB0639 and GB0226 parts (containing hCas9 and nptII transcriptional units, respectively) into the final destination vector. The final construct was then transformed into Agrobacterium tumefaciens strain LBA4404. The primers used are listened in supplementary Table S2.

\section{Plant transformation}

Arabidopsis transgenic plants were obtained using the floral dip method (Clough and Bent, 1998). Briefly, plants were grown under long day conditions until flower transition occurs and then the main stem was removed to allow growing of secondary meristems. Agrobacterium inoculation (C58C1 strain carrying construct of interest) was performed by immersion of the shoots (2-5 cm length) in a suspension containing $5 \%$ sucrose and $0.05 \%$ Silwet L-77. Transformant plants were selected in the presence of kanamycin and transferred to soil for further analyses.

489 Tomato transformants were obtained by in vitro co-cultivation of the Agrobacterium 490 strain LBA4404 (carrying the binary vector of interest) and cotyledon explants (Ellul et al., 2003). Transformants were selected in the presence of kanamycin and after rooting, transferred to the greenhouse. 
494 Genomic DNA was extracted from young leaves or unopened flower buds. A 530 bp 495 fragment from the SITPD1 genomic region flanking the targeted region was amplified using oligos SITPD1G For and SITPD1G Rev, purified and sequenced. T0 plants with percentages of edition over $80 \%$ were selected using the on line tool TiDE (http://shinyapps.datacurators.nl/tide/) (Brinkman et al 2014). We then used the on line software ICE v2 CRISPR analysis tool (https://ice.synthego.com/) to identify the number and type of edition for each plant.

501 For the genotyping of stable and Cas9-free edited plants, PCR-based molecular markers were designed. We used Cleaved Amplified Polymorphic Sequences (CAPS) markers

503 (Konieczny and Ausubel, 1993) that detect polymorphisms that occur in restriction 504 sites. The deletions present in the Sltpd1 $1^{\text {del2 }}$ and Sltpd1 $1^{\text {del5 }}$ allele, generated new restriction sites for BseGI and NcoI enzymes, respectively. Using SITPD1G For and SITPD1G Rev oligos (Table S2) a 530bp fragment was obtained from genomic DNA. BseGI generated two fragments of 308 bp and 220 bp in the Sltpd1 $1^{\text {del2 }}$ allele and NcoI generated two fragments of $299 \mathrm{bp}$ and 226 bp in the Sltpd $1^{\text {del5 }}$ allele. Neither of the enzymes cut the wild type fragment.

\section{Subcellular localization of SITPD1}

511 The coding sequence of SITPD1 was cloned via Gateway LR reaction into the 512 pEarleyGate101 vector (YFP fluorescent tag-containing)(Earley et al., 2006) to generate 513 the expression vector SITPD1-YFP. The vector was transformed into Agrobacterium 514 tumefaciens strain C58 and used to agroinfiltrate 4-weeks-old Nicotiana benthamiana 515 leaves. After 48 hours of the infiltration, the localization of the fluorescence fusion 516 protein was determined on leaf disks by confocal scanning microscopy (LSM 780, 517 Zeiss, Jena, Germany). A 35S:GFP construct was used as a control.

\section{Expression analyses by quantitative real-time PCR (qPCR)}

519 Total RNA was extracted from frozen tissue using the E.Z.N.A. Plant RNA Kit (Omega 520 BioTek). RNA was treated with DNAse I (Thermo Fisher Scientific) to remove 521 genomic DNA and quantified in a NanoDrop ND-1000 Spectophotometer (Thermo 522 Fisher Scientific). For first-strand cDNA synthesis, one microgram of DNase-treated 523 RNA was used for reverse transcription using a PrimerScript RT reagent kit (Takara) 
524 and a mix of oligo poli-dT and random hexamers. The resulting cDNA was used for 525 quantitative RT-PCR with the MasterMix qPCR ROX PyroTaq EvaGreen 5x (CmB) 526 and the reaction was run on a QuantStudio 3 (Applied Biosystems). Relative expression 527 levels were calculated by normalizing to the reference genes ACT (Arabidopsis 528 experiments) or SlActin8 (tomato experiments) and using the $\Delta \Delta \mathrm{Ct}$ method. All primers 529 showed amplification efficiencies between 90 and 110\%. The primers used are listed in 530 the supplementary Table S2.

\section{RNA in situ hybridization in tomato flowers.}

532 Fresh floral samples were fixed in FAE (4\% formaldehyde, 5\% acetic acid, 50\% 533 ethanol) overnight at $4^{\circ} \mathrm{C}$, and afterwards, stored in $70 \%$ ethanol. Samples were embedded in paraffin using an automated tissue processor (Leica TP1020).

To generate gene specific probes cDNA fragments were cloned under T7/SP6 promoter sequences. For SITPD1 a 284 bp DNA fragment from the 5' coding region was amplified by PCR using cDNA from flowers and cloned into the pGEM-T Easy vector

538 (Promega). For TomA5B and SISDS genes, we used cDNA fragment of 442 bp and 440 539 bp respectively. Digoxigenin-labelled probes were transcribed in vitro with T7 or SP6 540 RNA polymerases. RNA was hybridized in situ (Huijser et al., 1992; Gómez-Mena and Roque, 2018) in paraffin-embedded sections $(8 \mu \mathrm{m})$ and color was detected with 5bromo-4-chloroindol-3-yl phosphate/nitrateblue tetrazolium (BCIP/NBT) (Roche).

\section{Histological techniques}

544 For histological studies, tissue was fixed in FAE overnight at $4{ }^{\circ} \mathrm{C}$ and stored in $70 \%$ ethanol. Samples were embedded in acrylic resin (Technovit 7100; Kulzer) according to the manufacturer's instructions. For histological analysis, resin sections were stained with $0.05 \%$ toluidine blue in $0.1 \mathrm{M} 6.8 \mathrm{pH}$ phosphate buffer (O’Brien et al., 1964) and visualized in a Leica DM 5000B microscope (Leica Microsystems) under bright field.

\section{Aniline blue staining in cryosections}

550 For assays in which fresh tissue was needed, samples were fixed in NEG-50 (Richard 551 Alan Scientific), rapidly frozen in liquid nitrogen, and cut into $16 \mu \mathrm{m}$ sections using a 552 cryostat (Microm HM 520). Cryosections were stained for 10 minutes in the darkness 553 with $0.5 \%$ aniline blue in $0.07 \mathrm{mM}$ sodium phosphate buffer, and visualized in a Leica DM 5000B microscope (Leica Microsystems). 
556 Alexander's staining was carried out as previously described (Peterson et al., 2010) 557 with 2 minutes of incubation at $50^{\circ} \mathrm{C}$ on a hot plate. For pollen viability, pollen was 558 released from the anthers by squeezing, stained and counted. Samples were visualized in 559 a Leica DM 5000B (Leica Microsystems) microscope under bright field. For each 560 sample, thirty anthers from five different flowers were used.

Histochemical localization and quantification of hydrogen peroxide $\left(\mathrm{H}_{2} \mathrm{O}_{2}\right)$ and superoxide radical $\left(\mathrm{O}^{\circ}{ }^{-}\right)$

563 Hydrogen peroxide localization was performed in anthers obtained from flowers in 564 different developmental stages. Immediately after dissection, anthers were submerged in 565 a $1 \mathrm{mg} \mathrm{ml}^{-1} \mathrm{DAB}-\mathrm{HCl}(\mathrm{pH}$ 3.8) solution for 16 hours under light conditions (Unger et al., 2005), then cleared in $80 \%$ ethanol for 20 minutes and observed in a binocular microscope (Leica Microsystems). Hydrogen peroxide levels were quantified following a similar method. After staining in $\mathrm{DAB}-\mathrm{HCl}$ and clearing with ethanol, anthers were pulverized in liquid nitrogen, dissolved in $0.2 \mathrm{M} \mathrm{HClO}_{4}$ and centrifuged at $12000 \mathrm{~g}$ for 10 minutes. The absorbance of the supernatant was quantified at $450 \mathrm{~nm}$. $\mathrm{H}_{2} \mathrm{O}_{2}$ concentrations were obtained through a standard curve for known hydrogen peroxide concentrations diluted with 0.2 $\mathrm{M} \mathrm{HClO}_{4}-\mathrm{DAB}$ (Kotchoni et al., 2006).

Superoxide radical was measured as formazan formation over time from tetrazolium blue. Flowers from different developmental stages were weighted, submerged in $50 \mathrm{mM}$ potassium phosphate buffer ( $\mathrm{pH} 7.8$ ) containing $0.1 \%$ NBT and $10 \mathrm{mM}$ sodium azide, left to stain for 2 hours and cleared in 70\% ethanol. After staining, tissue was rapidly frozen in liquid nitrogen and ground. Formazan was selectively extracted using $200 \mu \mathrm{l}$ of DMSO and absorbance was measured at $550 \mathrm{~nm}$.

Peroxidase (PRX) and superoxide dismutase (SOD) activity

580 Flowers at different developmental stages were collected and frozen in liquid nitrogen.

581 Frozen tissue was ground and homogenized in extraction buffer $(0.1 \mathrm{M}$ Tris $\mathrm{pH} 7.0$, $5820.1 \%$ ascorbic acid, 0.1\% L-cysteine, $0.5 \mathrm{M}$ sucrose and $10 \mathrm{mg} / \mathrm{ml} \mathrm{PVP}$ ) and centrifuged 583 at $4^{\circ} \mathrm{C}$ for 15 minutes, saving the supernatant. Total protein was quantified using the 584 Bradford method (Bradford, 1976). Briefly, $10 \mu \mathrm{l}$ of crude extract were added to a tube 585 containing $1 \mathrm{ml}$ of Bradford solution (0.01\% Coomasie Brilliant Blue G-250, 4.7\% 
586 ethanol, 8.5\% phosphoric acid) and mixed. After two minutes, the absorbance was 587 measured at $595 \mathrm{~nm}$. A standard curve was generated using known concentrations of 588 BSA.

589 For SOD activity, $25 \mathrm{mg}$ of protein from the crude extract were added to $1 \mathrm{ml}$ of SOD 590 buffer (50mM PBS pH7.6, 0.01mM EDTA, 50mM sodium carbonate, 12mM L591 methionine, $10 \mu \mathrm{M}$ riboflavin, $50 \mu \mathrm{M}$ NBT) and incubated at room temperature under 592 light conditions for 10 minutes. Absorbance was measured at $550 \mathrm{~nm}$ and SOD buffer 593 without extract was used as a negative control. SOD activity was quantified as the 594 amount of enzyme required to inhibit $50 \%$ of the photoreduction of NBT.

595 For PRX activity, 25 to $75 \mathrm{mg}$ of protein from the crude extract were added to $1 \mathrm{ml}$ of 596 PRX buffer (0.85 mM hydrogen peroxide in HEPES pH7.0, 0.125M 4-aminoantipyrene, $5978.1 \mathrm{mg} / \mathrm{ml}$ phenol) and the change in absorbance was measured for 2 minutes at $510 \mathrm{~nm}$. 598 A standard curve was generated using known concentrations of horseradish peroxidase. RNA-Seq analyses

600 Total RNA was extracted from stage 8 stamens from the wild type and Sltpd1 plants. 601 Frozen tissue using a NucleoSpin RNA Plant kit (Mascheny-Nagel) and measured in a NanoDrop ND-1000 Spectophotometer (Thermo Fisher Scientific). The RNA quality was assessed based on the RNA integrity number (RIN) using Bioanalyzer 2100

604

605

606

607

608

609

610

611

612 (Agilent) and samples with RIN $>8$ were selected for the experiment. RNA sequencing was performed using the BGISEQ Technology platform at BGI (China). A total of three biological replicates were used for each sample set. GO enrichment, KEGG enrichment and statistical analysis were done through the Dr. Tom platform (BGI, China).

\section{Statistical analysis}

IBM SPSS Statistics v.27 was used for statistical analysis. For each data set, a ShapiroWilk normality test was run. For normally distributed data, a Student-t test was used for pairwise comparison. Non-normally distributed data were analyzed with a MannWhitney test.

\section{SUPPLEMENTAL DATA}

Figure S1. Expression pattern of two tomato TPD1 gene homologs analyzed by quantitative RT-PCR in leaves and floral buds at different developmental stages. 
616 Figure S2. In silico analyses of Arabidopsis and tomato TPD1 gene homologs.

617 Figure S3. Expression of SITPD1 in the ovary detected using in situ hybridization.

618 Figure S4. Characterization of CRISP/Cas9-mediated SITPD1 edited tomato plants.

619 Table S1. Accession numbers of TPD1-like gene sequences from different plant species

620 used for the phylogenetic analysis.

621 Table S2. Oligonucleotides used in this study.

622 Table S3. List of differentially expressed genes (DEGs) between wild-type and Sltpd1

623 mutant anthers from floral stage 8.

624

625 ACKNOWLEDGMENTS

626 This work was supported by grant RTI2018-094280-B-I00 funded by MCIN/AEI/ 627 10.13039/501100011033 and by FEDER “A way of making Europe”. We thank 628 Aureliano Bombarely for his help in the conversion of gene IDs into Solyc identifiers, 629 Diego Orzáez for providing GoldenBraid parts and Maricruz Rochina for expert 630 technical assistance during the project. 
632 Table 1. List of genes involved pollen development and reactive oxygen species (ROS) 633 homeostasis that showed down regulation in the anthers of Sltpd1 mutants compared to 634 the wild type at floral stage 8.

\begin{tabular}{|c|c|c|c|}
\hline Gene ID & Gene homologue & $\log 2$ & Qvalue \\
\hline \multicolumn{4}{|c|}{ Anther wall tapetum development } \\
\hline Solyc02g079810 & Transcription factor DYT1 & -6.43964989 & $1.26 \mathrm{E}-76$ \\
\hline Solyc08g062780 & Transcription factor Aborted Microspores & -7.58989677 & $3.02 \mathrm{E}-21$ \\
\hline Solyc03g059200 & MYB35 & -8.14777345 & $4.14 \mathrm{E}-62$ \\
\hline Solyc01g081100 & Transcription factor bHLH91-like & -9.19738196 & $7.73 \mathrm{E}-64$ \\
\hline \multicolumn{4}{|c|}{ Other genes related to pollen and anther development } \\
\hline Solyc06g074320 & Transcription factor TGA9 & -0.9158745 & 1.48E-19 \\
\hline Solyc12g010170 & Transcription factor bHLH66 & -1.24356281 & 0.0094393 \\
\hline Solyc03g113850 & Protein Jingubang & -2.52418827 & 2.03E-08 \\
\hline Solyc03g117800 & Eceriferum 3 & -2.69271178 & $2.41 E-39$ \\
\hline Solyc06g051950 & Bobber 1 & -2.94998503 & $3.36 \mathrm{E}-04$ \\
\hline Solyc07g063180 & Dynein light chain & -2.99548166 & $3.63 E-32$ \\
\hline Solyc03g120650 & Pollen-specific kinase partner protein & -3.03837744 & $2.86 \mathrm{E}-04$ \\
\hline Solyc01g005510 & L-ascorbate oxidase homolog & -3.41385131 & 0.0328411 \\
\hline Solyc07g052300 & MYB101 & -4.56110971 & $2.39 \mathrm{E}-13$ \\
\hline Solyc04g056360 & Probable WRKY transcription factor 3 & -6.45522912 & $6.88 \mathrm{E}-24$ \\
\hline \multicolumn{4}{|c|}{ Sporopollenin biosynthesis and pollen exine formation } \\
\hline Solyc02g068400 & Polygalacturonase QRT3 & -2.224485 & $5.13 \mathrm{E}-12$ \\
\hline Solyc01g111070 & Type III polyketide synthase B & -4.43900397 & $6.36 \mathrm{E}-11$ \\
\hline Solyc03g051960 & Fatty acyl-CoA reductase 2 & -6.20323505 & $1.05 \mathrm{E}-08$ \\
\hline Solyc04g008780 & Tetraketide alpha-pyrone reductase 1 & -8.93478906 & $5.77 \mathrm{E}-28$ \\
\hline Solyc02g088710 & 4-coumarate-CoA ligase-like 1 & -9.02558469 & $1.29 \mathrm{E}-17$ \\
\hline Solyc01g090600 & Type III polyketide synthase $A$ & -9.20644722 & $6.19 \mathrm{E}-11$ \\
\hline Solyc10g009390 & Cytochrome P450 703A2 & -9.84385813 & $1.02 \mathrm{E}-17$ \\
\hline Solyc07g015960 & Spermidine hydroxycinnamoyl transferase & -10.5269673 & $3.00 \mathrm{E}-14$ \\
\hline Solyc01g010900 & Cytochrome P450 704B1 & -10.8055292 & $2.24 \mathrm{E}-10$ \\
\hline Solyc03g053130 & Strictosidine synthase-like 13 & -11.9186345 & 4.75E-11 \\
\hline \multicolumn{4}{|c|}{$\begin{array}{ll}\text { ROS- related genes } \\
\end{array}$} \\
\hline Solyc06g074320 & Transcription factor TGA9 & -0.9158745 & $1.48 \mathrm{E}-19$ \\
\hline Solyc02g083620 & L-ascorbate peroxidase 5 & -0.99116313 & 0.0195753 \\
\hline Solyc08g062450 & Class II small heat shock protein Le-HSP17.6 & -1.28889207 & $8.78 \mathrm{E}-04$ \\
\hline Solyc07g048070 & Cytochrome b561 & -1.80370303 & $4.43 E-05$ \\
\hline Solyc02g084780 & Peroxidase 72 & -2.03908491 & 0.0020332 \\
\hline Solyc01g104860 & Peroxidase 43-like & -2.50327644 & 0.0209080 \\
\hline Solyc01g090710 & cMDH (cytosolic malate dehydrogenase) & -3.30689847 & $2.74 \mathrm{E}-15$ \\
\hline Solyc01g005510 & L-ascorbate oxidase homolog & -3.41385131 & 0.0328411 \\
\hline Solyc08g036570 & Glutaredoxin-C9-like (MIL1) & -3.43941376 & $1.62 \mathrm{E}-07$ \\
\hline Solyc03g031880 & Probable polyamine oxidase 4 & -4.51662449 & $9.01 E-34$ \\
\hline Solyc10g047110 & Peroxidase 43-like & -4.55372011 & $2.86 \mathrm{E}-08$ \\
\hline Solyc08g075320 & Abscisic acid 8'-hydroxylase 3 & -4.57900097 & $2.79 \mathrm{E}-04$ \\
\hline Solyc03g078810 & UDP-glycosyltransferase 76B1-like & -4.58408135 & $5.30 \mathrm{E}-11$ \\
\hline Solyc07g042460 & Respiratory burst oxidase homolog protein $\mathrm{E}$ & -4.83360202 & 5.37E-05 \\
\hline Solyc05g051730 & Monothiol glutaredoxin-S6-like & -4.83448598 & 0.0398049 \\
\hline Solyc01g099620 & Respiratory burst oxidase homolog protein $A$ & -4.90590784 & $2.61 \mathrm{E}-45$ \\
\hline Solyc04g080760 & Peroxidase 9 & -4.98729283 & 4.09E-68 \\
\hline Solyc07g052550 & Peroxidase 3-like & -5.23971051 & $3.43 \mathrm{E}-07$ \\
\hline Solyc10g078670 & bZIP transcription factor TGA10-like & -5.24607495 & $1.22 \mathrm{e}-27$ \\
\hline Solyc10g076190 & Peroxidase 2-like & -6.05039275 & 0.0078115 \\
\hline Solyc02g014730 & Cytochrome P450 86B1 & -6.07748043 & $3.81 \mathrm{E}-06$ \\
\hline Solyc01g058520 & Peroxidase 40 & -6.67248882 & 0 \\
\hline Solyc10g009390 & Cytochrome P450 703A2 & -9.84385813 & $1.02 \mathrm{E}-17$ \\
\hline
\end{tabular}


636 Figure 1. Solyc03g097530 (SITPD1) encodes the ortholog of TPD1 in tomato. A, 637 Unrooted neighbor-joining tree of TPD1-like proteins. The numbers next to the internal 638 nodes are bootstrap values from 1000 pseudo-replicates. B, Amino acid sequence 639 alignment between the Arabidopsis and tomato gene homologs. The putative signal 640 peptides are underlined, the six conserved cysteine residues are in bold and the potential 641 dibasic cleavage site is highlighted with a red square. C, Subcellular localization of 642 SITPD1 protein in Nicotiana benthamiana leaves as observed by confocal microscopy. $643 \mathrm{D}$, Complementation of the male sterile floral phenotype of the Arabidopsis tpd1 mutant 644 using SITPD1 gene. All the tpd1; pTPD1:SITPD1 plants showed viable pollen. Scale 645 bars in (D) correspond to $500 \mu \mathrm{m}$.

646 Figure 2. Expression of SITPD1 during plant development. A, Relative expression of SITPD1 in different plant tissues analysed by qPCR. Data were normalized to the expression of ACT10 gene and correspond to the mean $( \pm \mathrm{SD})$ of three biological replicates. B-G, Localization of SITPD1 transcript by in situ hybridization on reproductive meristems and developing flowers. St6: floral stage 6; St8: floral stage 8; St10: floral stage 10; St12: floral stage 12; St14: floral stage 14. SC: Sporogenous cells; MT: microspore tetrads; T: Tapetum; Mp: microspores; P: mature polen.

Figure 3. Mutations in SITPD1 result in empty anthers and seedless fruits. A, Guide RNA (in blue) was targeted to the third exon of SITPD1. B, Wild-type and Sltpd1 flowers and opened fruits. Sltpd1 plants showed flowers with protruding pistils (arrow) and seedless fruits. Scale bar: $0.5 \mathrm{~cm}$. C, Fruit weight and shape (width/height ration) of the wild type, Sltpd1 ${ }^{\text {Del5 }}$ and Sltpd1 ${ }^{\text {Del2 }}$ plants ( $\mathrm{n} \geq 40 \pm \mathrm{SD}$ ).

Figure 4. Pollen development is impaired in Sltpd1 mutants. A-L, Histological sections of anther from the wild type (a-c and g-i) and Sltpd1 mutant (D-F and J-L) at different developmental stages. Transveral section of anthers from floral stage 6 (A) and (D), floral stage 8 (B) and (E), floral stage 10 (C) and (F), floral stage 12 (G) and (J), floral stage $14(\mathrm{H})$ and $(\mathrm{K})$ and floral stage 16 (I and L). Floral stages have been named according to Brukhin et al 2003. Scale bar: 50 m. Ep: epidermis; En: endotecium; ML: 664 middle layers; SC: sporogenous cells; T: tapetum; Td: tetrads; Mp: microspores; P: 665 mature pollen. 
666 Figure 5. Sltpd1 mutant anthers specifically lack tapetal cells. A, In situ hybridization of the tapetum marker TomA5B in wild type and Sltpd1 anthers. B, In situ hybridization of the meiosis marker SISDS in wild type and Sltpd1 anthers at floral stage 8. C, Callose deposition in anthers as observed by aniline blue staining of wild type and Sltpd1. St8: floral stage 8; St10: floral stage 10; St12: floral stage 12. Scale bar: $50 \mu \mathrm{m}$ in (A) and (B); $100 \mu \mathrm{m}$ in (C).

Figure 6. Global gene expression chages in the anthers of Sltpd1 mutants at floral stage 8 in comparison with the wild type. A, Total number of DEGs between wild type and mutant anthers. B, GO biological process enrichment analysis. C, Expression heatmap of differentially expressed genes involved in pollen and anther development. D, Expression heatmap of differentially expressed ROS-related genes. Q-value $<0.05$; pvalue $<0.05$.

Figure 7. Expression pattern of genes involved in redox homeostais during anther development of the wild type and Sltpd1 mutant plants. Quantitative RT-PCR of (A) SIRbohA/Solyc01g099620 gene;

(B) SlRbohE/Solyc06g075570 gene; RBOH1SIRbohG/Solyc08g081690 gene;

(D) SlGRX9/Solyc08g036570 gene; (E) SITGA9/Solyc06g074320 gene and

(F) SITGA10/Solyc10g078670 gene. Data correspond to three biological replicates \pm SD. Statistical differences were inferred using a Mann-Whitney test. $(*)=\mathrm{p}<0.05,(* *)=\mathrm{p}<0.01,(* * *)=\mathrm{p}<0.001$.

Figure 8. Redox homeostasis is altered in Sltpd1 mutant anthers. Quantification of superoxide anion (O2.- $\cdot^{-}$levels (A) and $\mathrm{H}_{2} \mathrm{O}_{2}$ levels (B) in wild-type and Sltpd1 anthers at different developmental stages $(n=3 \pm S D)$. Quantification of superoxide dismutase (C) and peroxidase (D) activity in wild-type and Sltpd1 flowers at different developmental stages (St6-St20). Data correspond to 3 biological replicates \pm SD. Statistical differences were inferred using a Mann-Whitney test. $\left({ }^{*}\right)=p<0.05,\left({ }^{* *}\right)=$ $p<0.01$.

Figure 9. Working model summarizing the genetic elements of the redox network affected by the absence of SITPD1 and the concomitant tapetum loss, at early stages of tomato anther development. Enzymatic ROS accumulation (Orange) is attenuated by 695 ROS scavenging mechanism (Pink). Changes in ROS levels activate signalling pathways (Blue) that result in the induction of genes involved in anther/pollen 
698

699

700

701

702

703

704

705

706

707

708

709

710

711

712

713

714

715

716

717

718

719

RBOH: Respiratory burst oxidase homolog; SOD: superoxide dismutase; TGAs: TGA transcription factors.

\section{REFERENCES}

Aguirre PJ, Smith AG (1993) Molecular characterization of a gene encoding a cysteine-rich protein preferentially expressed in anthers of Lycopersicon esculentum. Plant Mol Biol 23: 477-487

Åstrand J, Knight C, Robson J, Talle B, Wilson ZA (2021) Evolution and diversity of the angiosperm anther: trends in function and development. Plant Reprod. doi: 10.1007/s00497-021-00416-1

\section{Aya K, Tanaka MU, Kondo M, Hamada K, Yano K, Nishimura M, Matsuoka M} (2009) Gibberellin modulates anther development in rice via the transcriptional regulation of GAMYB. Plant Cell 21: 1453-1472

Azumi Y, Liu D, Zhao D, Li W, Wang G, Hu Y, Ma H (2002) Homolog interaction during meiotic prophase I in Arabidopsis requires the SOLO DANCERS gene encoding a novel cyclin-like protein. EMBO J 21: 3081-3095

\section{Bai W, Wang P, Hong J, Kong W, Xiao Y, Yu X, Zheng H, You S, Lu J, Lei D, et} al (2019) Earlier degraded tapetum1 (EDT1) encodes an ATP-citrate lyase required for tapetum programmed cell death. Plant Physiol 181: 1223-1238

Van Bel M, Diels T, Vancaester E, Kreft L, Botzki A, Van De Peer Y, Coppens F, Vandepoele K (2018) PLAZA 4.0: An integrative resource for functional, evolutionary and comparative plant genomics. Nucleic Acids Res 46: D1190D1196

Bradford MM (1976) A rapid and sensitive method for the quantitation of microgram quantities of protein utilizing the principle of protein-dye binding. Anal Biochem 72: $248-254$

\section{Brukhin V, Hernould M, Gonzalez N, Chevalier C, Mouras A (2003) Flower} development schedule in tomato Lycopersicon esculentum cv. sweet cherry. Sex Plant Reprod 15: 311-320 
Canales C, Bhatt AM, Scott R, Dickinson H (2002) EXS, a putative LRR receptor kinase, regulates male germline cell number and tapetal identity and promotes seed development in Arabidopsis. Curr Biol 12: 1718-1727

Chang F, Wang Y, Wang S, Ma H (2011) Molecular control of microsporogenesis in Arabidopsis. Curr Opin Plant Biol 14: 66-73

\section{Chen W, Lv M, Wang Y, Wang PA, Cui Y, Li M, Wang R, Gou X, Li J (2019)} BES1 is activated by EMS1-TPD1-SERK1/2-mediated signaling to control tapetum development in Arabidopsis thaliana. Nat Commun. doi: 10.1038/s41467019-12118-4

Clough SJ, Bent AF (1998) Floral dip: a simplified method for Agrobacteriummediated transformation of Arabidopsis thaliana. Plant J 16: 735-743

Cui J, You C, Zhu E, Huang Q, Ma H, Chang F (2016) Feedback regulation of DYT1 by interactions with downstream bHLH factors promotes DYT1 Nuclear localization and anther development. Plant Cell 28: 1078-1093

Dukowic-Schulze S, van der Linde K (2021) Oxygen, secreted proteins and small RNAs: mobile elements that govern anther development. Plant Reprod. doi: 10.1007/s00497-020-00401-0

\section{Earley KW, Haag JR, Pontes O, Opper K, Juehne T, Song K, Pikaard CS (2006)} Gateway-compatible vectors for plant functional genomics and proteomics. Plant J 45: $616-629$

Ellul P, Garcia-Sogo B, Pineda B, Ríos G, Roig LA, Moreno V (2003) The ploidy level of transgenic plants in Agrobacterium-mediated transformation of tomato cotyledons (Lycopersicon esculenturn L.Mili.) is genotype and procedure dependent. Theor Appl Genet 106: 231-238

Gómez-Mena C, Roque EM (2018) Non-isotopic RNA in situ hybridization for functional analyses in Medicago truncatula. Methods Mol Biol. doi: 10.1007/9781-4939-8633-0_10

Gómez JF, Talle B, Wilson ZA (2015) Anther and pollen development: A conserved developmental pathway. J Integr Plant Biol 57: 876-891 
W, Hellsten U, Putnam N, et al (2012) Phytozome: A comparative platform for green plant genomics. Nucleic Acids Res 40: 1178-1186

Gorman SW, McCormick S (1997) Male Sterility in Tomato. CRC Crit Rev Plant Sci 16: $31-53$

Gu JN, Zhu J, Yu Y, Teng XD, Lou Y, Xu XF, Liu JL, Yang ZN (2014) DYT1 directly regulates the expression of TDF1 for tapetum development and pollen wall formation in Arabidopsis. Plant J 80: 1005-1013

Hao S, Ariizumi T, Ezura H (2017) Sexual sterility is essential for both male and female gametogenesis in tomato. Plant Cell Physiol 58: 22-34

\section{Hong L, Tang D, Shen Y, Hu Q, Wang K, Li M, Lu T, Cheng Z (2012a) MIL2} (MICROSPORELESS2) regulates early cell differentiation in the rice anther. New Phytol 196: 402-413

Hong L, Tang D, Zhu K, Wang K, Li M, Cheng Z (2012b) Somatic and reproductive cell development in rice anther is regulated by a putative glutaredoxin. Plant Cell 24: $577-588$

Huang H, Ullah F, Zhou DX, Yi M, Zhao Y (2019) Mechanisms of ROS regulation of plant development and stress responses. Front Plant Sci 10: 1-10

Huang J, Wijeratne AJ, Tang C, Zhang T, Fenelon RE, Owen HA, Zhao D (2016a) Ectopic expression of TAPETUM DETERMINANT1 affects ovule development in Arabidopsis. J Exp Bot 67: 1311-1326

Huang J, Zhang T, Linstroth L, Tillman Z, Otegui MS, Owen HA, Zhao D (2016b) Control of Anther Cell Differentiation by the Small Protein Ligand TPD1 and Its Receptor EMS1 in Arabidopsis. PLoS Genet 12: 1-29

\section{Huijser P, Klein J, Lönnig WE, Meijer H, Saedler H, Sommer H (1992)}

Bracteomania, an inflorescence anomaly, is caused by the loss of function of the MADS-box gene squamosa in Antirrhinum majus. EMBO J 11: 1239-1249

Ito T, Shinozaki K (2002) The MALE STERILITY1 gene of Arabidopsis, encoding a nuclear protein with a PHD-finger motif, is expressed in tapetal cells and is required for pollen maturation. Plant Cell Physiol. doi: 10.1093/pcp/pcf154 
Jacobowitz JR, Doyle WC, Weng JK (2019) PRX9 and PRX40 are extensin peroxidases essential for maintaining tapetum and microspore cell wall integrity during arabidopsis anther development. Plant Cell 31: 848-861

Jaffri SRF, MacAlister CA (2021) Sequential Deposition and Remodeling of Cell Wall Polymers During Tomato Pollen Development. Front Plant Sci. doi: 10.3389/fpls.2021.703713

Jeong HJ, Kang JH, Zhao M, Kwon JK, Choi HS, Bae JH, Lee HA, Joung YH, Choi D, Kang BC (2014) Tomato Male sterile 1035 is essential for pollen development and meiosis in anthers. J Exp Bot 65: 6693-6709

Kelliher T, Walbot V (2012) Hypoxia triggers meiotic fate acquisition in maize. Science (80- ) 337: 345-348

Konieczny A, Ausubel FM (1993) A procedure for mapping Arabidopsis mutations using co-dominant ecotype-specific PCR-based markers. Plant J 4: 403-410

Kotchoni SO, Kuhns C, Ditzer A, Kirch HH, Bartels D (2006) Over-expression of different aldehyde dehydrogenase genes in Arabidopsis thaliana confers tolerance to abiotic stress and protects plants against lipid peroxidation and oxidative stress. Plant, Cell Environ 29: 1033-1048

Labroo MR, Studer AJ, Rutkoski JE (2021) Heterosis and Hybrid Crop Breeding: A Multidisciplinary Review. Front Genet 12: 1-19

Lei X, Liu B (2020) Tapetum-Dependent Male Meiosis Progression in Plants: Increasing Evidence Emerges. Front Plant Sci 10: 1-10

van der Linde K, Walbot V (2019) Pre-meiotic anther development, 1st ed. Curr Top Dev Biol. doi: 10.1016/bs.ctdb.2018.11.001

\section{Liu X, Yang M, Liu X, Wei K, Cao X, Wang X, Wang X, Guo Y, Du Y, Li J, et al} (2019) A putative bHLH transcription factor is a candidate gene for male sterile 32, a locus affecting pollen and tapetum development in tomato. Hortic Res. doi: 10.1038/s41438-019-0170-2

Liu Z, Shi X, Li S, Hu G, Zhang L, Song X (2018) Tapetal-delayed programmed cell death (PCD) and oxidative stress-induced male sterility of aegilops uniaristata cytoplasm in wheat. Int J Mol Sci. doi: 10.3390/ijms19061708 
Medina M, Roque E, Pineda B, Cañas L, Rodriguez-Concepción M, Beltrán JP, Gómez-Mena C (2013) Early anther ablation triggers parthenocarpic fruit development in tomato. Plant Biotechnol J 11: 770-779

Millar AA, Gubler F (2005) The Arabidopsis GAMYB-like Genes, MYB33 and MYB65, are microRNA-regulated genes that redundantly facilitate anther development. Plant Cell 17: 705-721

Mittler R (2017) ROS Are Good. Trends Plant Sci 22: 11-19

Molesini B, Dusi V, Pennisi F, Pandolfini T (2020) How hormones and mads-box transcription factors are involved in controlling fruit set and parthenocarpy in tomato. Genes (Basel) 11: 1-17

Murmu J, Bush MJ, de Long C, Li S, Xu M, Khan M, Malcolmson C, Fobert PR, Zachgo S, Hepworth SR (2010) Arabidopsis basic leucine-zipper transcription factors TGA9 and TGA10 interact with floral glutaredoxins ROXY1 and ROXY2 and are redundantly required for anther development. Plant Physiol 154: 14921504

\section{Nonomura K-I, Miyoshi K, Eiguchi M, Suzuki T, Miyao A, Hirochika H, Kurata N} (2003) The MSP1 Gene Is Necessary to Restrict the Number of Cells Entering into Male and Female Sporogenesis and to Initiate Anther Wall Formation in Rice Published by : American Society of Plant Biologists ( ASPB ) Linked references are available on JSTOR for t. Plant Cell 15: 1728-1739

O’Brien TP, Feder N, McCully ME (1964) Polychromatic staining of plant cell walls by toluidine blue O. Protoplasma 59: 368-373

\section{Okabe Y, Yamaoka T, Ariizumi T, Ushijima K, Kojima M, Takebayashi Y,} Sakakibara H, Kusano M, Shinozaki Y, Pulungan SI, et al (2019) Aberrant Stamen Development is Associated with Parthenocarpic Fruit Set Through UpRegulation of Gibberellin Biosynthesis in Tomato. Plant Cell Physiol. doi: 10.1093/pcp/pcy184

Oliveros JC, Franch M, Tabas-Madrid D, San-León D, Montoliu L, Cubas P, Pazos F (2016) Breaking-Cas-interactive design of guide RNAs for CRISPR-Cas experiments for ENSEMBL genomes. Nucleic Acids Res 44: W267-W271 
Pacini E, Cresti M (1978) Ultrastructural characteristics of the tapetum and microspore mother cells in Lycopersicum peruvianum during meiotic prophase . Bull la Société Bot Fr Actual Bot 125: 121-128

Peterson R, Slovin JP, Chen C (2010) A simplified method for differential staining of aborted and non-aborted pollen grains. Int J Plant Biol 1: 66-69

Rhee SY, Osborne E, Poindexter PD, Somerville CR (2003) Microspore Separation in the quartet 3 Mutants of Arabidopsis Is Impaired by a Defect in a Developmentally Regulated Polygalacturonase Required for Pollen Mother Cell Wall Degradation. Plant Physiol 133: 1170-1180

\section{Rojas-Gracia P, Roque E, Medina M, Rochina M, Hamza R, Angarita-Díaz MP,} Moreno V, Pérez-Martín F, Lozano R, Cañas L, et al (2017) The parthenocarpic hydra mutant reveals a new function for a SPOROCYTELESS-like gene in the control of fruit set in tomato. New Phytol 214: 1198-1212

\section{Sagi M, Davydov O, Orazova S, Yesbergenova Z, Ophir R, Stratmann JW, Fluhr} R (2004) Plant respiratory burst oxidase homologs impinge on wound responsiveness and development in Lycopersicon esculentum. Plant Cell 16: 616628

\section{Sheridan WF, Avalkina NA, Shamrov II, Batygina TB, Golubovskaya IN (1996)}

The mac1 gene: Controlling the commitment to the meiotic pathway in maize. Genetics 142: 1009-1020

Song JJ, Rhee JG, Suntharalingam M, Walsh SA, Spitz DR, Lee YJ (2002) Role of glutaredoxin in metabolic oxidative stress: Glutaredoxin as a sensor of oxidative stress mediated by H2O2. J Biol Chem 277: 46566-46575

Sorensen AM, Kröber S, Unte US, Huijser P, Dekker K, Saedler H (2003) The Arabidopsis ABORTED MICROSPORES (AMS) gene encodes a MYC class transcription factor. Plant J 33: 413-423

Tamura K, Stecher G, Peterson D, Filipski A, Kumar S (2013) MEGA6: Molecular evolutionary genetics analysis version 6.0. Mol Biol Evol 30: 2725-2729

Unger C, Kleta S, Jandl G, Tiedemann A V. (2005) Suppression of the defencerelated oxidative burst in bean leaf tissue and bean suspension cells by the 
necrotrophic pathogen Botrytis cinerea. J Phytopathol 153: 15-26

877

878

Vivian-Smith A, Koltunow AM (1999) Genetic analysis of growth-regulator-induced parthenocarpy in Arabidopsis. Plant Physiol. doi: 10.1104/pp.121.2.437

\section{Wang CJR, Nan GL, Kelliher T, Timofejeva L, Vernoud V, Golubovskaya IN,} Harper L, Egger R, Walbot V, Zacheus Cande W (2012) Maize multiple archesporial cells 1 (mac1), an ortholog of rice TDL1A, modulates cell proliferation and identity in early anther development. Dev 139: 2594-2603

Wilson ZA, Zhang DB (2009) From arabidopsis to rice: Pathways in pollen development. J Exp Bot 60: 1479-1492

Xie HT, Wan ZY, Li S, Zhang Y (2014) Spatiotemporal production of reactive oxygen species by nadph oxidase is critical for tapetal programmed cell death and pollen development in Arabidopsis. Plant Cell 26: 2007-2023

Xing S, Zachgo S (2008) ROXY1 and ROXY2, two Arabidopsis glutaredoxin genes, are required for anther development. Plant J 53: 790-801

\section{Yan MY, Xie DL, Cao JJ, Xia XJ, Shi K, Zhou YH, Zhou J, Foyer CH, Yu JQ} (2020) Brassinosteroid-mediated reactive oxygen species are essential for tapetum degradation and pollen fertility in tomato. Plant J 102: 931-947

Yang S-L, Xie L-F, Mao H-Z, Puah CS, Yang W-C, Jiang L, Sundaresan V, Ye D (2003) TAPETUM DETERMINANT1 Is Required for Cell Specialization in the Arabidopsis Anther. Plant Cell 15: 2792 LP - 2804

Yang SL, Jiang L, Puah CS, Xie LF, Zhang XQ, Chen LQ, Yang WC, Ye D (2005) Overexpression of TAPETUM DETERMINANT1 alters the cell fates in the Arabidopsis carpel and tapetum via genetic interaction with EXCESS MICROSPOROCYTES1/EXTRA SPOROGENOUS CELLS. Plant Physiol 139: 186-191

Yang X, Li G, Tian Y, Song Y, Liang W, Zhang D (2018) A rice glutamyl-tRNA synthetase modulates early anther cell division and patterning. Plant Physiol 177: $728-744$

Yu J, Zhang D (2019) Molecular Control of Redox Homoeostasis in Specifying the Cell Identity of Tapetal and Microsporocyte Cells in Rice. Rice. doi: 
Zhang D, Yang L (2014) Specification of tapetum and microsporocyte cells within the anther. Curr Opin Plant Biol 17: 49-55

Zhao DZ, Wang GF, Speal B, Ma H (2002) The EXCESS MICROSPOROCYTES1 gene encodes a putative leucine-rich repeat receptor protein kinase that controls somatic and reproductive cell fates in the Arabidopsis anther. Genes Dev 16: 2021-2031

Zhao X, De Palma J, Oane R, Gamuyao R, Luo M, Chaudhury A, Hervé P, Xue Q, Bennett J (2008) OsTDL1A binds to the LRR domain of rice receptor kinase MSP1, and is required to limit sporocyte numbers. Plant J 54: 375-387 
Figure 1. Solyc03g097530 (SITPD1) encodes the ortholog of TPD1 in tomato. A, Unrooted neighbor-joining tree of TPD1-like proteins. The numbers next to the internal nodes are bootstrap values from 1000 pseudo-replicates. B, Amino acid sequence alignment between the Arabidopsis and tomato gene homologs. The putative signal peptides are underlined, the six conserved cysteine residues are in bold and the potential dibasic cleavage site is highlighted with a red square. C, Subcellular localization of SITPD1 protein in Nicotiana benthamiana leaves as observed by confocal microscopy. D, Complementation of the male sterile floral phenotype of the Arabidopsis tpd1 mutant using SITPD1 gene. All the tpd1; pTPD1:SITPD1 plants showed viable pollen. Scale bars in (D) correspond to $500 \mu \mathrm{m}$.

A

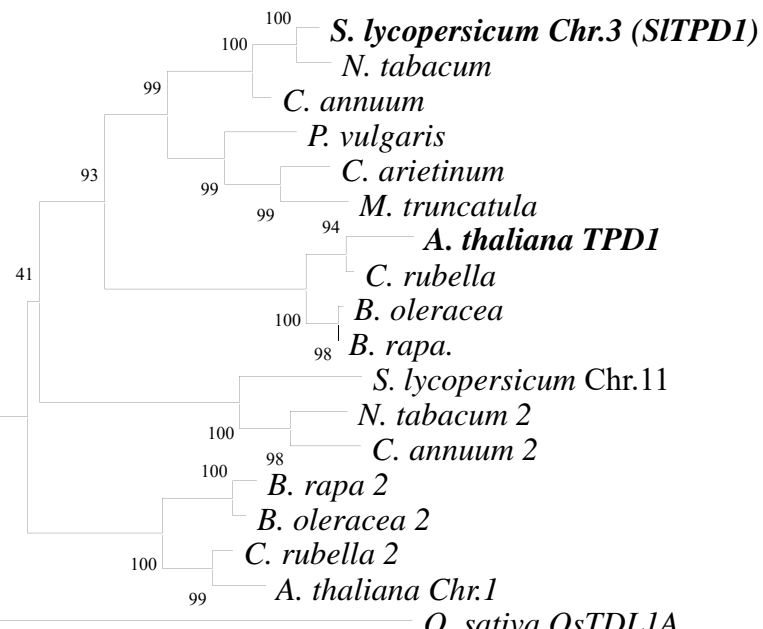

O. sativa OsTDL1A
B

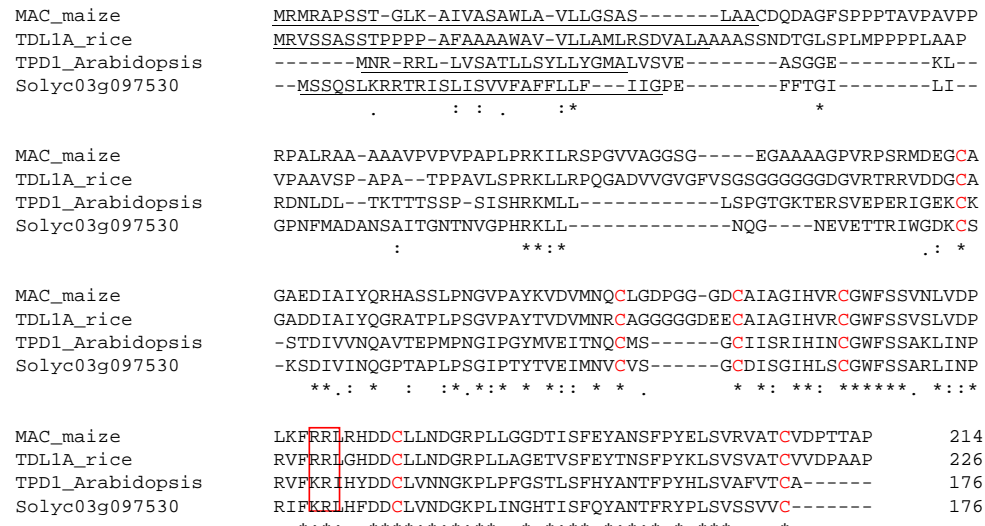

RIFKRL HFDDCLVNDGKPLINGHTISFOYANTFRYPLSVSSVVC
UV

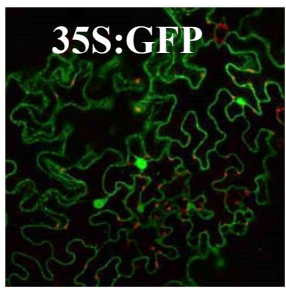

-SITPD1-YFP

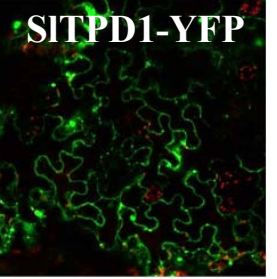

Bright field
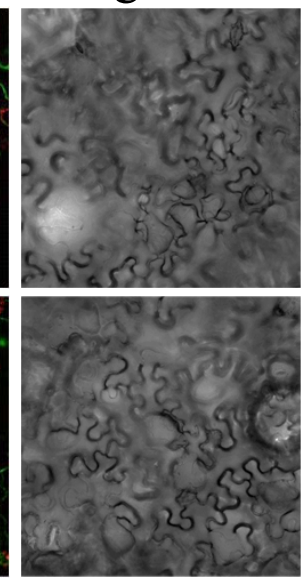

Merge
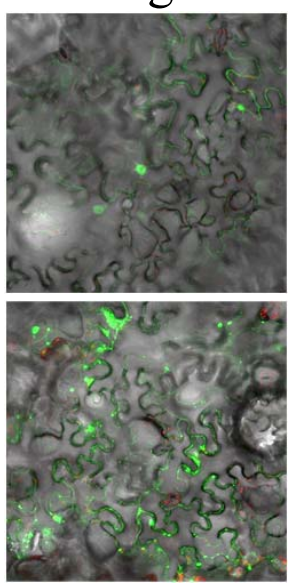

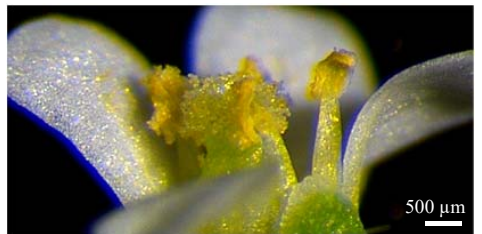

Wild type

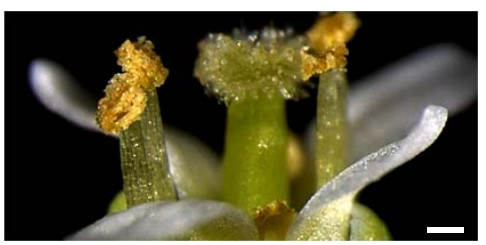

tpd1; pTPD1:SITPD1

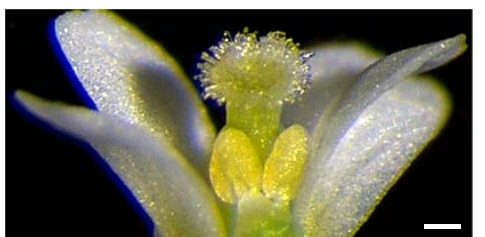

tpd1

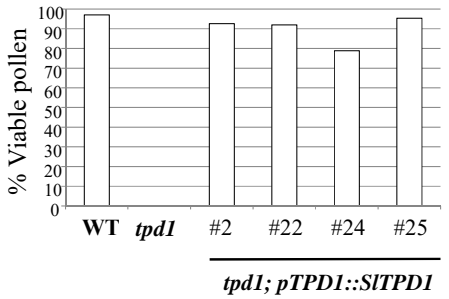


Figure 2. Expression of SITPD1 during plant development. A, Relative expression of SITPD1 in different plant tissues analysed by qPCR. Data were normalized to the expression of ACT10 gene and correspond to the mean $( \pm \mathrm{SD})$ of three biological replicates. B-G, Localization of SITPD1 transcript by in situ hybridization on reproductive meristems and developing flowers. St6: floral stage 6; St8: floral stage 8; St10: floral stage 10; St12: floral stage 12; St14: floral stage 14. SC: Sporogenous cells; MT: microspore tetrads; T: Tapetum; Mp: microspores; P: mature polen.

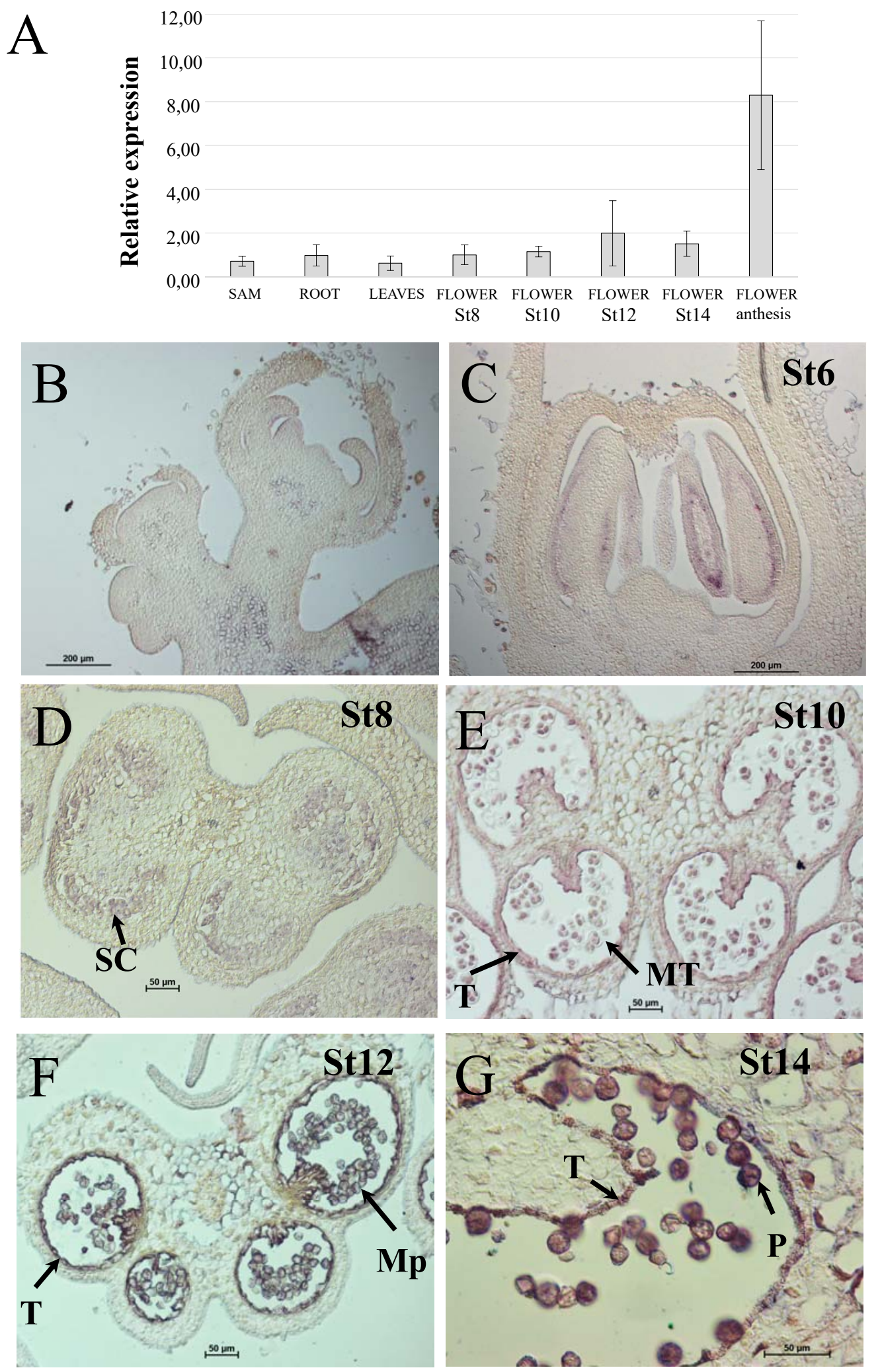


Figure 3. Mutations in SITPD1 result in empty anthers and seedless fruits. A, Guide RNA (in blue) was targeted to the third exon of SITPD1. B, Wild-type and Sltpd1 flowers and opened fruits. Sltpd1 plants showed flowers with protruding pistils (arrow) and seedless fruits. Scale bar: $0.5 \mathrm{~cm}$. C, Fruit weight and shape (width/height ration) of the wild type, Sltpd1 ${ }^{\text {Del5 }}$ and Sltpd1 ${ }^{\text {Del2 }}$ plants $(\mathrm{n} \geq 40 \pm \mathrm{SD})$.

A

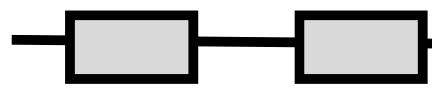

GTGGAAACAACCCGGATATG

\begin{tabular}{cl}
\hline Line & \multicolumn{1}{c}{ Sequence } \\
\hline WT & GGTGCAGGAAATGAAGTGGAACAACCCGGATATGGGGTGACA \\
\hline Sltpd1 ${ }^{\text {Del5 }}$ & GGTGCAGGAAATGAAGTGGAAACAACC- - - - ATGGGGTGACA \\
\hline Sltpd1 ${ }^{\text {Del2 }}$ & GGTGCAGGAAATGAAGTGGAAACAACCCGG- - ATGGGGTGACA \\
\hline
\end{tabular}

B

C
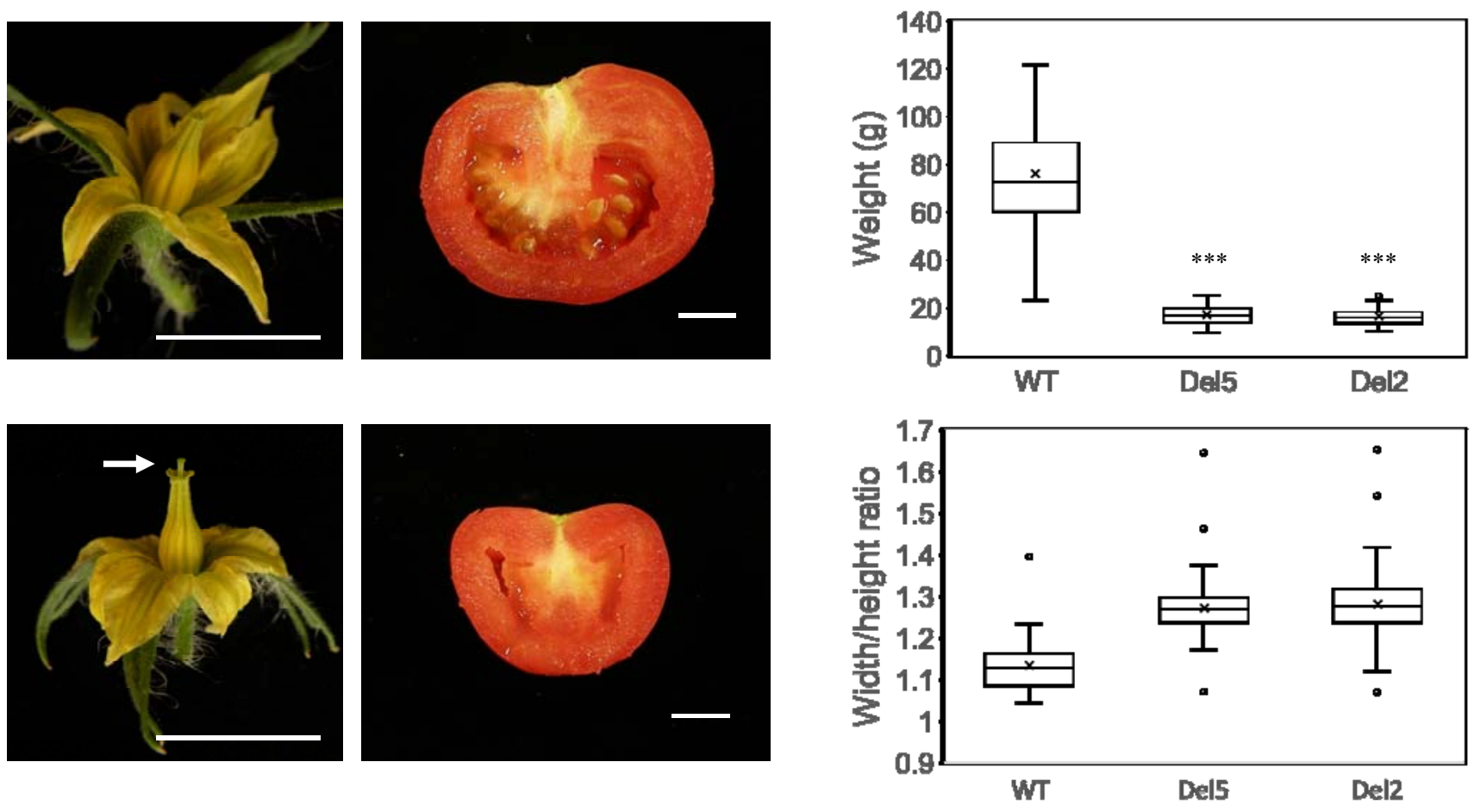
Figure 4. Pollen development is impaired in Sltpd1 mutants. A-L, Histological sections of anther from the wild type (a-c and g-i) and Sltpd1 mutant (D-F and J$\mathrm{L})$ at different developmental stages. Transveral section of anthers from floral stage $6(\mathrm{~A})$ and $(\mathrm{D})$, floral stage $8(\mathrm{~B})$ and $(\mathrm{E})$, floral stage $10(\mathrm{C})$ and $(\mathrm{F})$, floral stage $12(\mathrm{G})$ and $(\mathrm{J})$, floral stage $14(\mathrm{H})$ and $(\mathrm{K})$ and floral stage $16(\mathrm{I}$ and $\mathrm{L})$. Floral stages have been named according to Brukhin et al 2003. Scale bar: $50 \mu \mathrm{m}$. Ep: epidermis; En: endotecium; ML: middle layers; SC: sporogenous cells; T: tapetum; Td: tetrads; Mp: microspores; P: mature pollen.
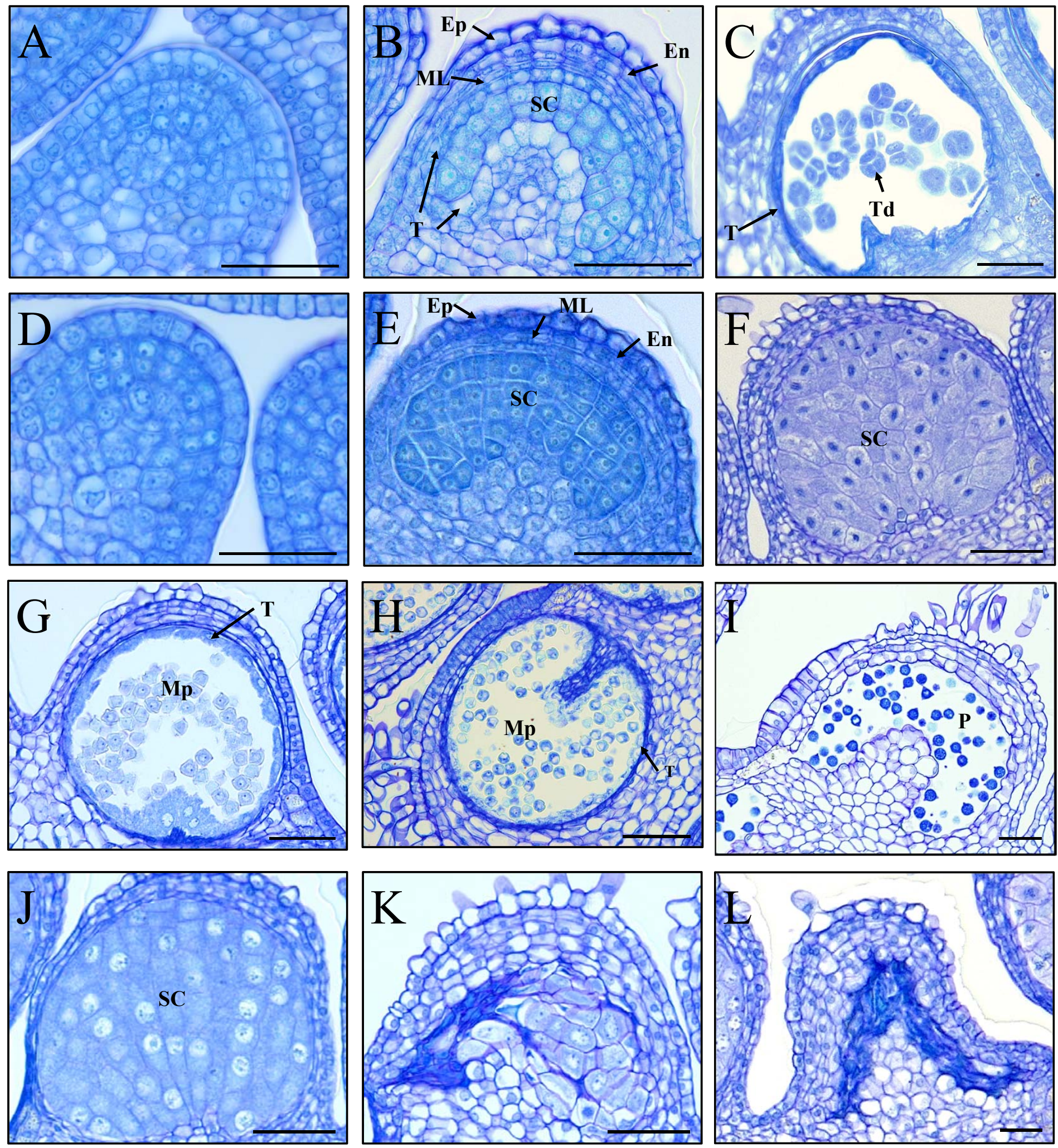
Figure 5. Sltpd1 mutant anthers specifically lack tapetal cells. A, In situ hybridization of the tapetum marker TomA5B in wild type and Sltpd1 anthers. B, In situ hybridization of the meiosis marker SISDS in wild type and Sltpd1 anthers at floral stage 8. C, Callose deposition in anthers as observed by aniline blue staining of wild type and Sltpd1. St8: floral stage 8; St10: floral stage 10; St12: floral stage 12. Scale bar: $50 \mu \mathrm{m}$ in (A) and (B); $100 \mu \mathrm{m}$ in (C).

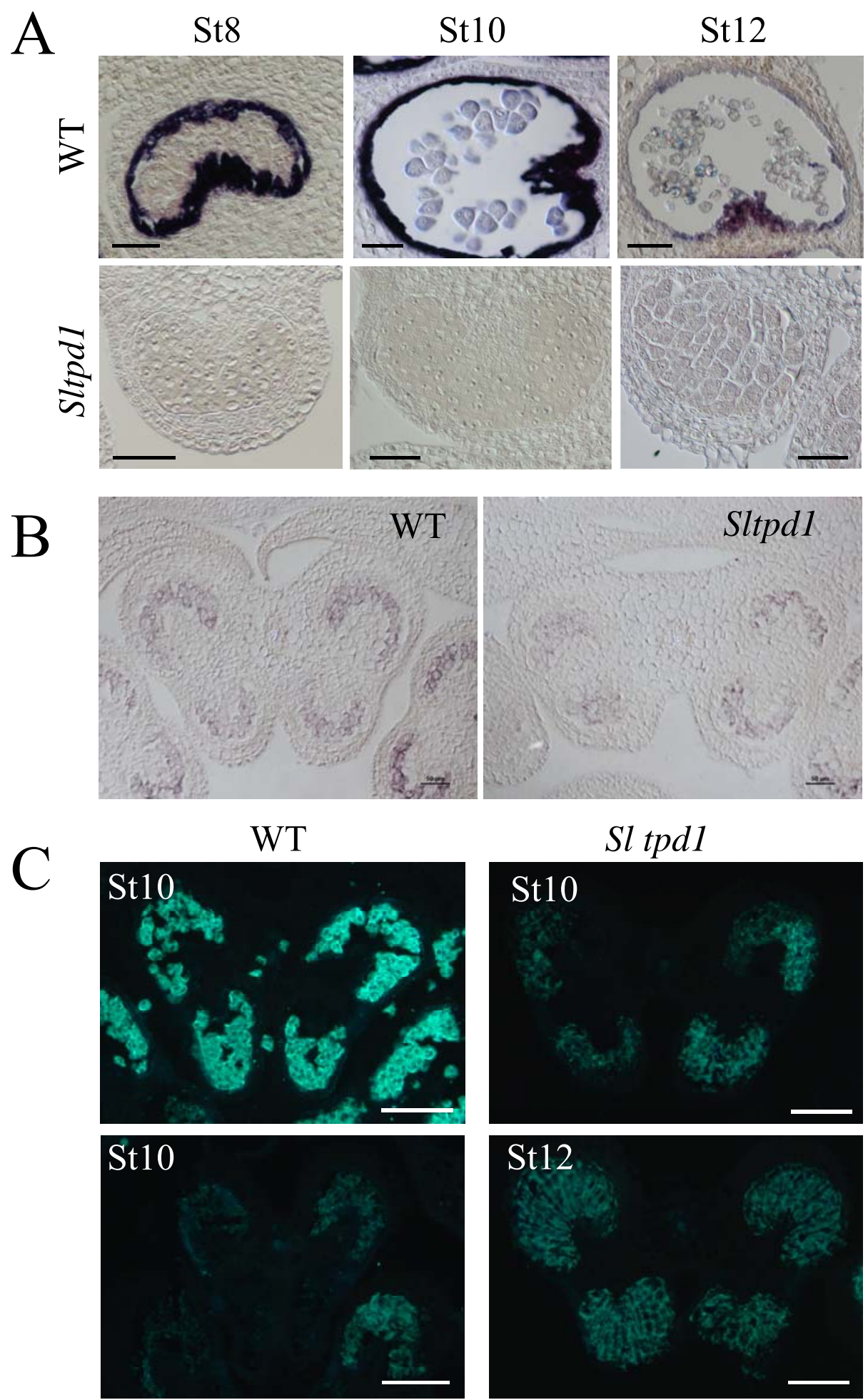


Figure 6. Global gene expression chages in the anthers of Sltpd1 mutants at floral stage 8 in comparison with the wild type. A, Total number of DEGs between wild type and mutant anthers. B, GO biological process enrichment analysis. C, Expression heatmap of differentially expressed genes involved in pollen and anther development. D, Expression heatmap of differentially expressed ROSrelated genes. Q-value $<0.05 ; \mathrm{p}$-value $<0.05$.

A

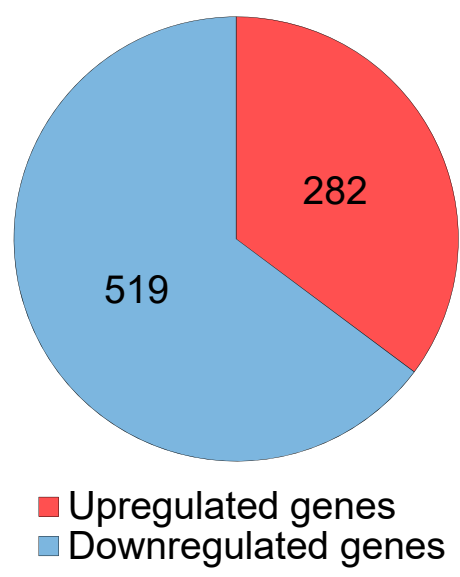

C

Pollen and anther development

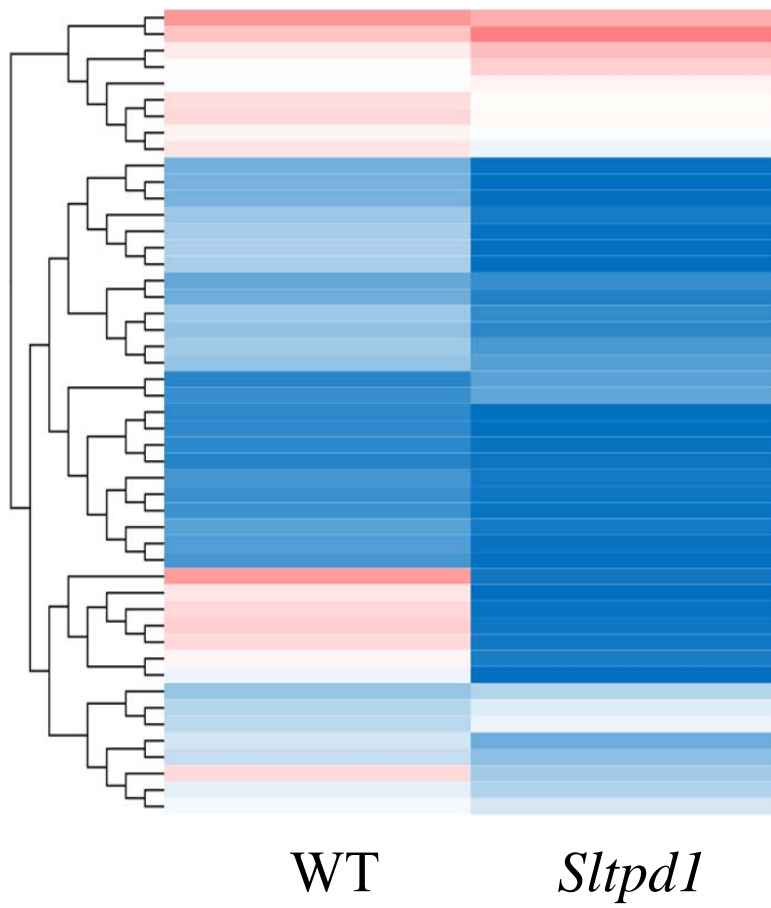

B

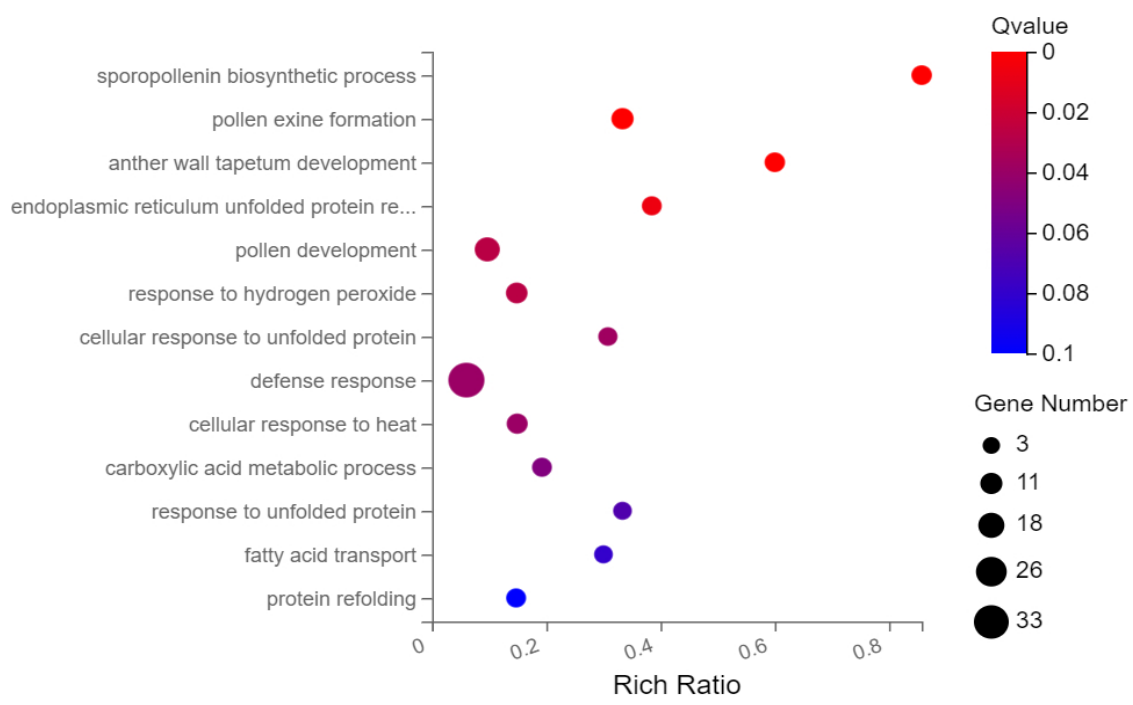

$\mathrm{D}$

ROS-related genes
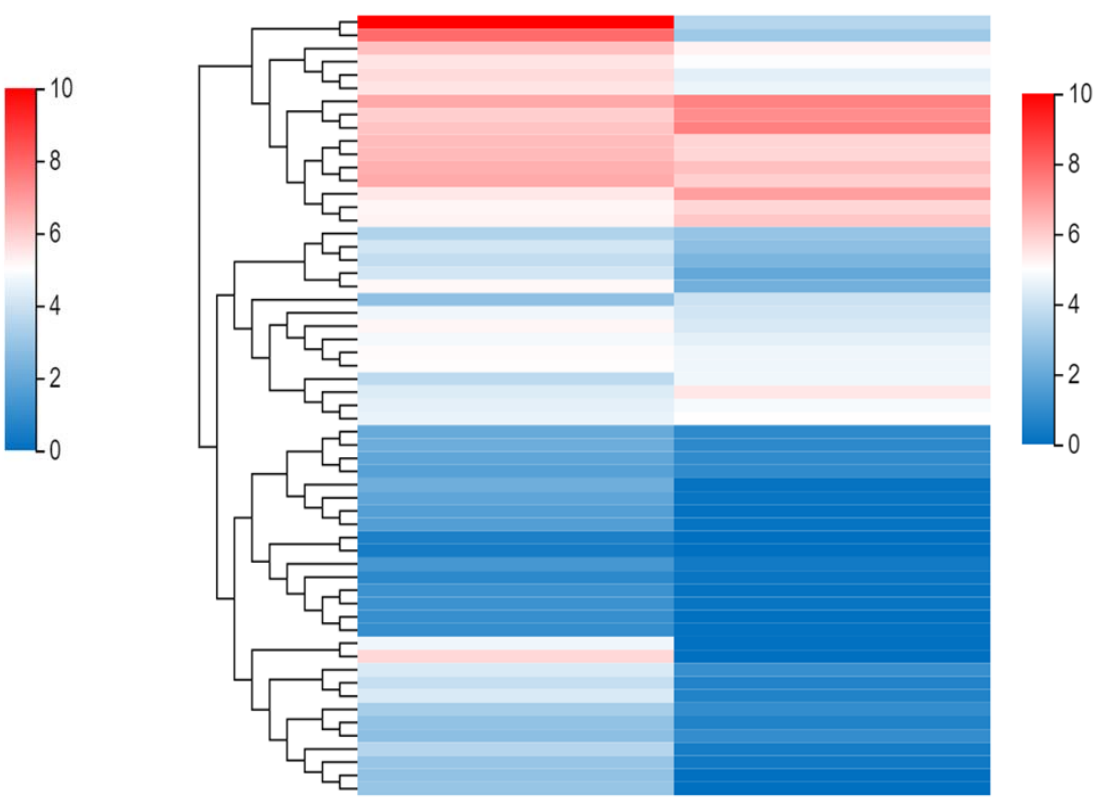

WT

Sltpd1 
Figure 7. Expression pattern of genes involved in redox homeostais during anther development of the wild type and SItpd1 mutant plants. Quantitative RT-PCR of (A) SIRbohA/Solyc01g099620 gene; (B) SIRbohE/Solyc06g075570 gene; RBOH1SIRbohG/Solyc08g081690 gene; (D) SIGRX9/Solyc08g036570 gene; SITGA9/Solyc06g074320 gene and (F) SITGA10/Solyc10g078670 gene. Data correspond to three biological replicates \pm SD. Statistical differences were inferred using a Mann-Whitney test. $\left({ }^{*}\right)=p<0.05,\left({ }^{* *}\right)=p<0.01,\left(^{* * *}\right)=p<0.001$.

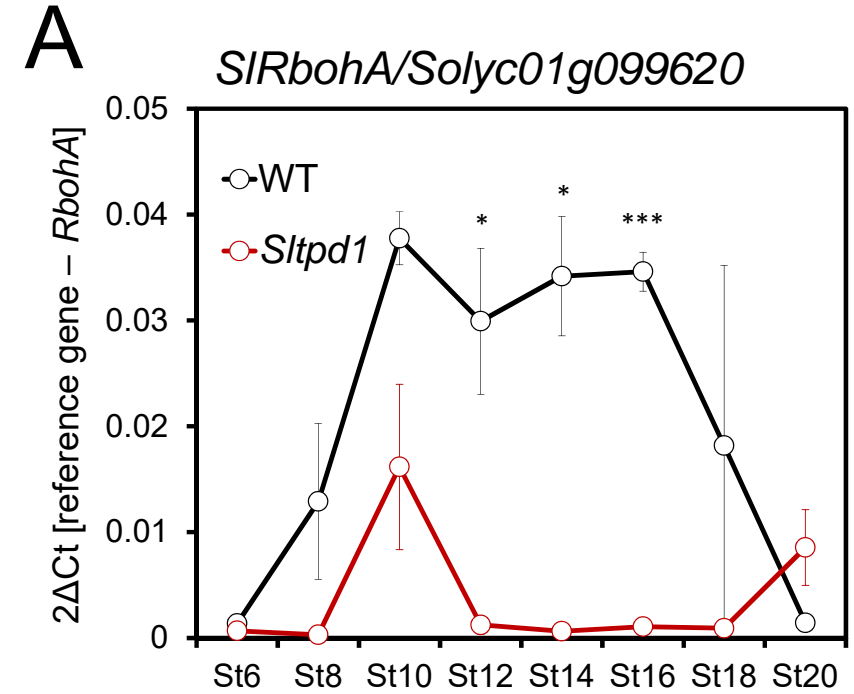

0
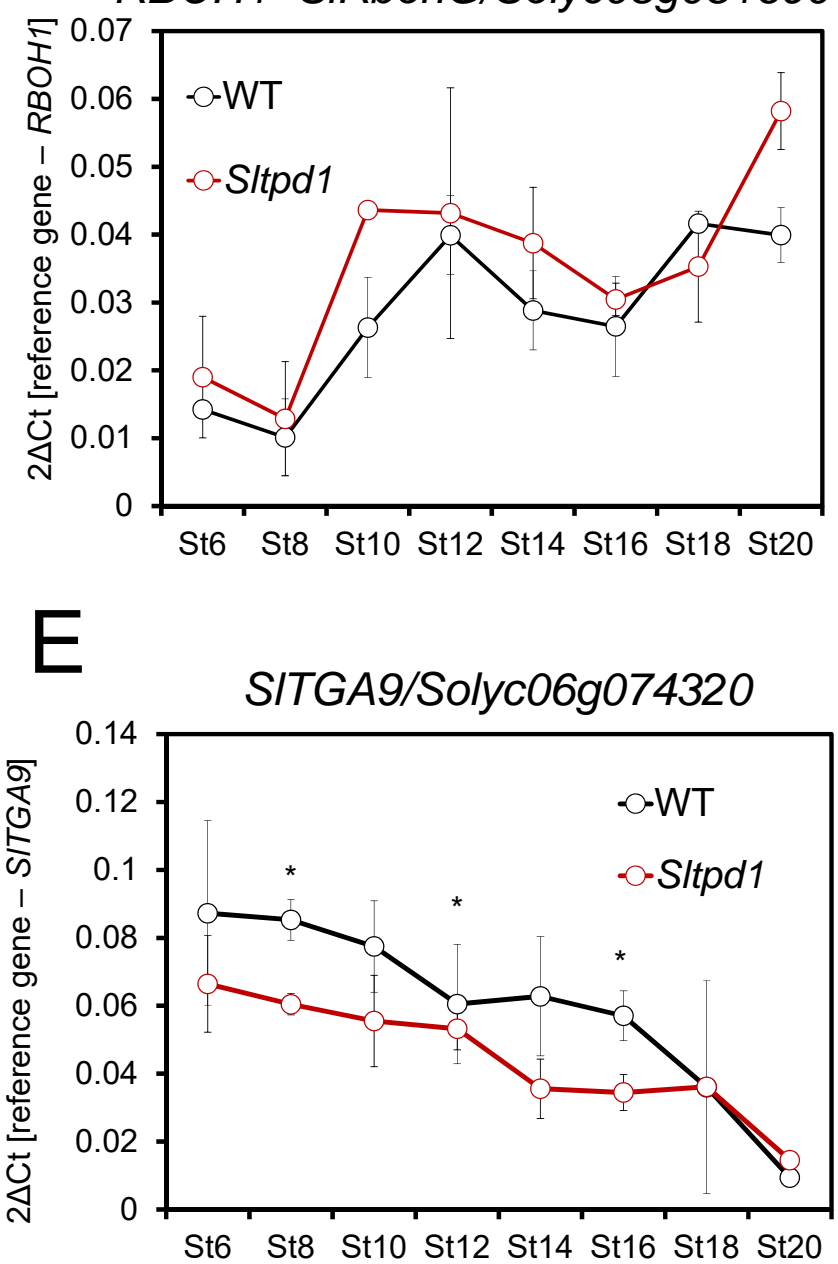

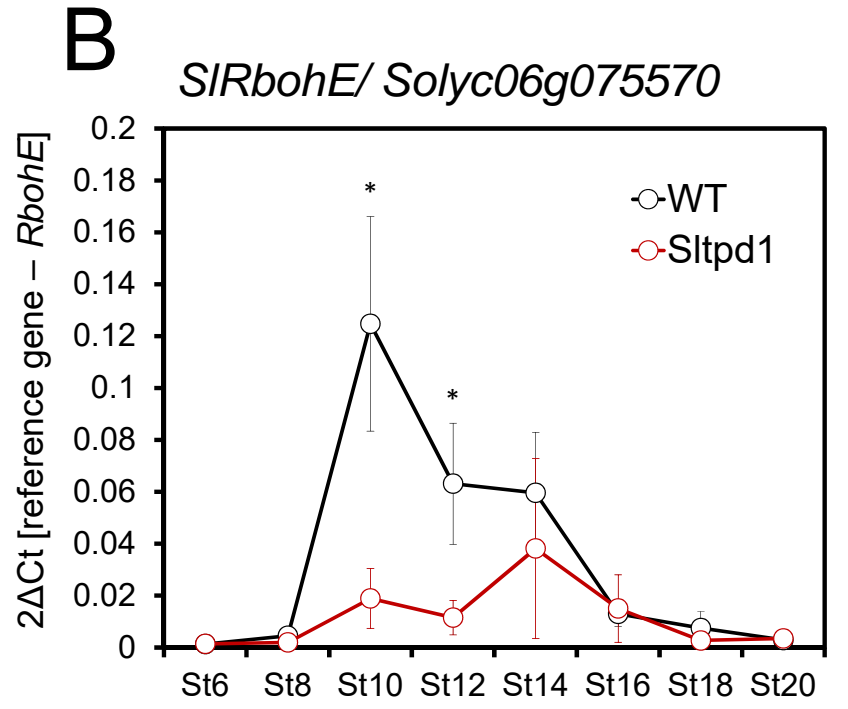

$D$

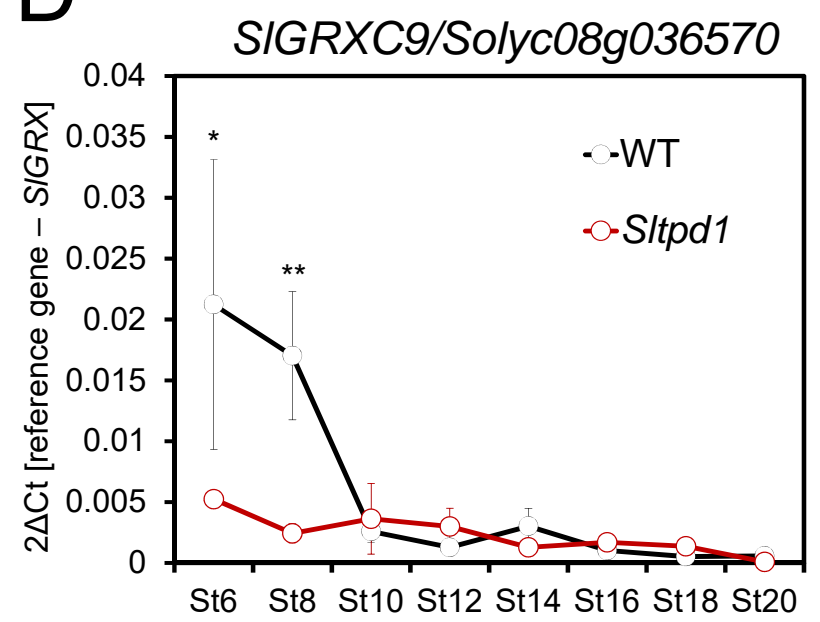

$E$

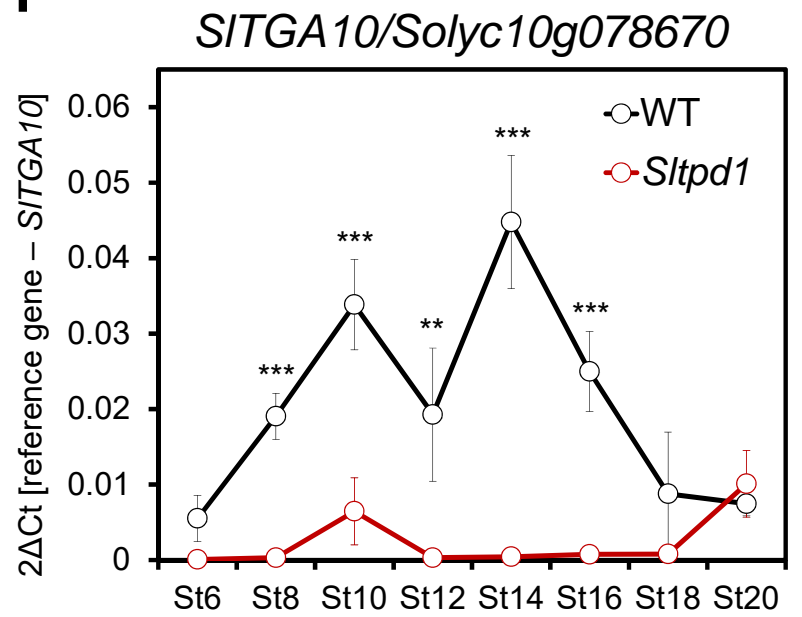


Figure 8. Redox homeostasis is altered in Sltpd1 mutant anthers. Quantification of superoxide anion (O2*-) levels (A) and $\mathrm{H}_{2} \mathrm{O}_{2}$ levels (B) in wild-type and Sltpd1 anthers at different developmental stages $(\mathrm{n}=3 \pm \mathrm{SD})$. Quantification of superoxide dismutase (C) and peroxidase (D) activity in wildtype and Sltpd1 flowers at different developmental stages (St6-St20). Data correspond to 3 biological replicates $\pm \mathrm{SD}$. Statistical differences were inferred using a Mann-Whitney test. $\left({ }^{*}\right)=p<0.05,\left({ }^{* *}\right)=p<0.01$.

A

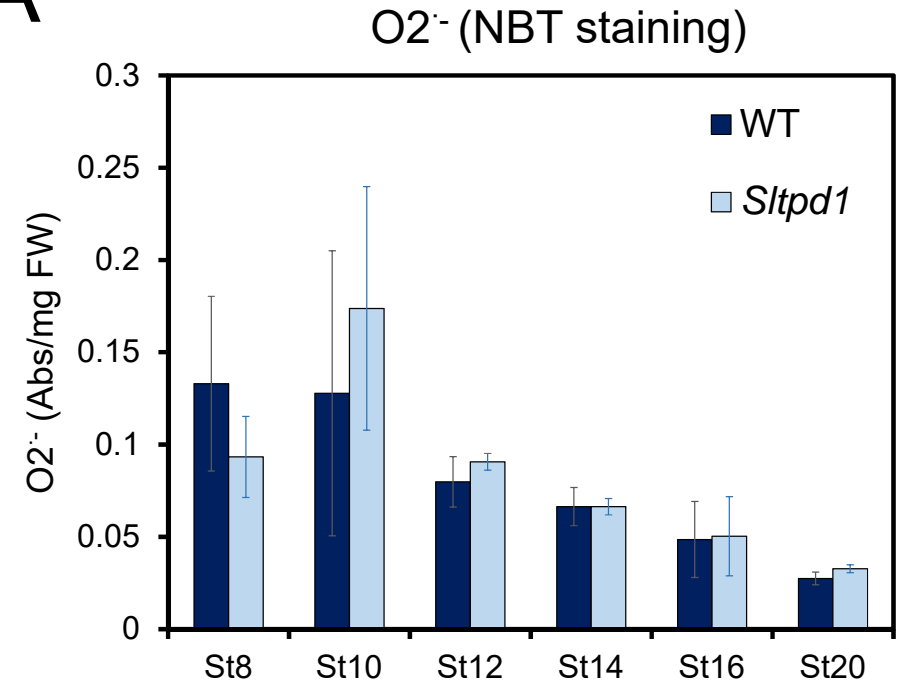

C

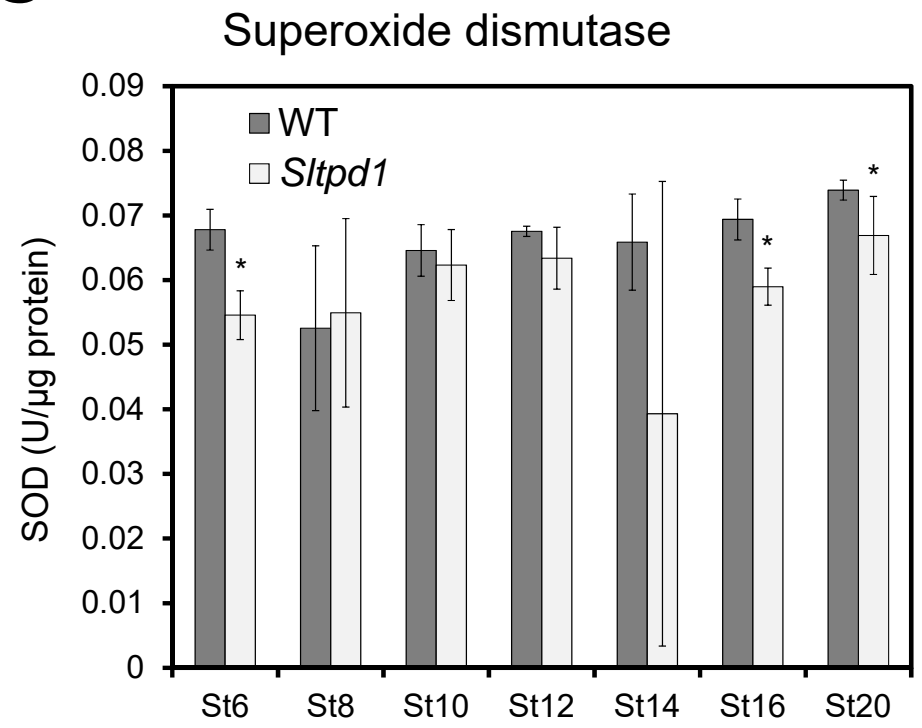

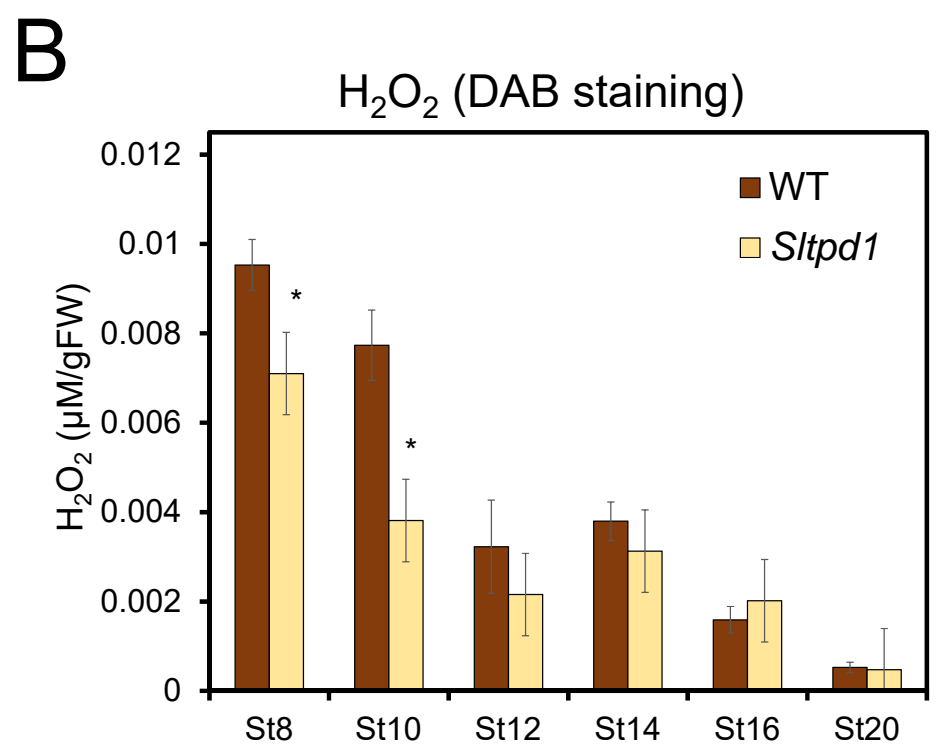

$\mathrm{D}$

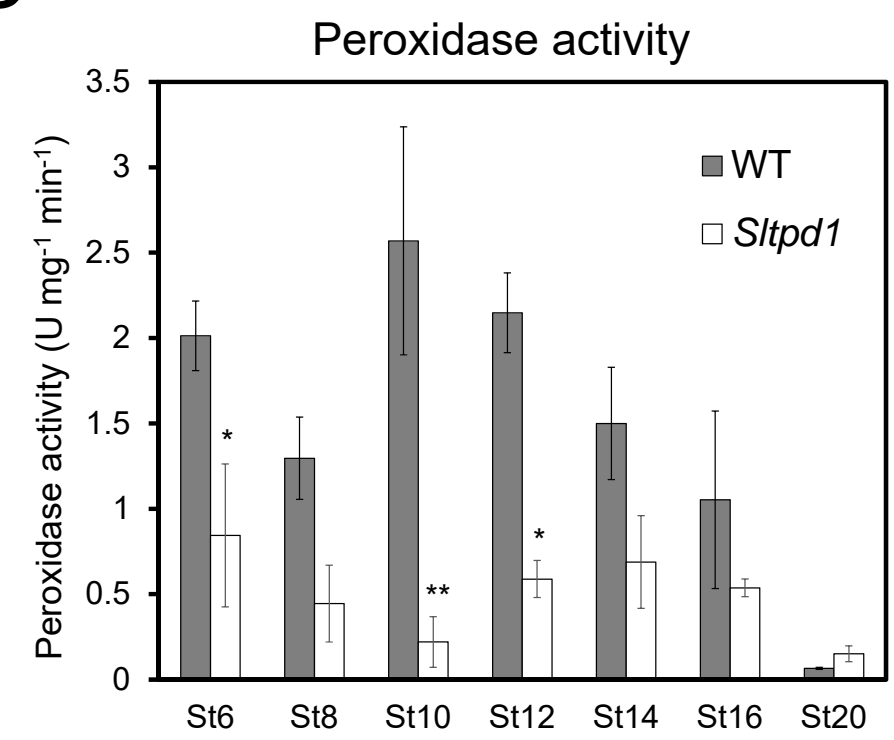


Figure 9. Working model summarizing the genetic elements of the redox network affected by the absence of SITPD1 and the concomitant tapetum loss, at early stages of tomato anther development. Enzymatic ROS accumulation (Orange) is attenuated by ROS scavenging mechanism (Pink). Changes in ROS levels activate signaling pathways (Blue) that result in the induction of genes involved in anther/pollen development. APX: ascorbate peroxidase; GRXs: glutaredoxins; PRX: peroxidases; RBOH: Respiratory burst oxidase homolog; SOD: superoxide dismutase; TGAs: TGA transcription factors.

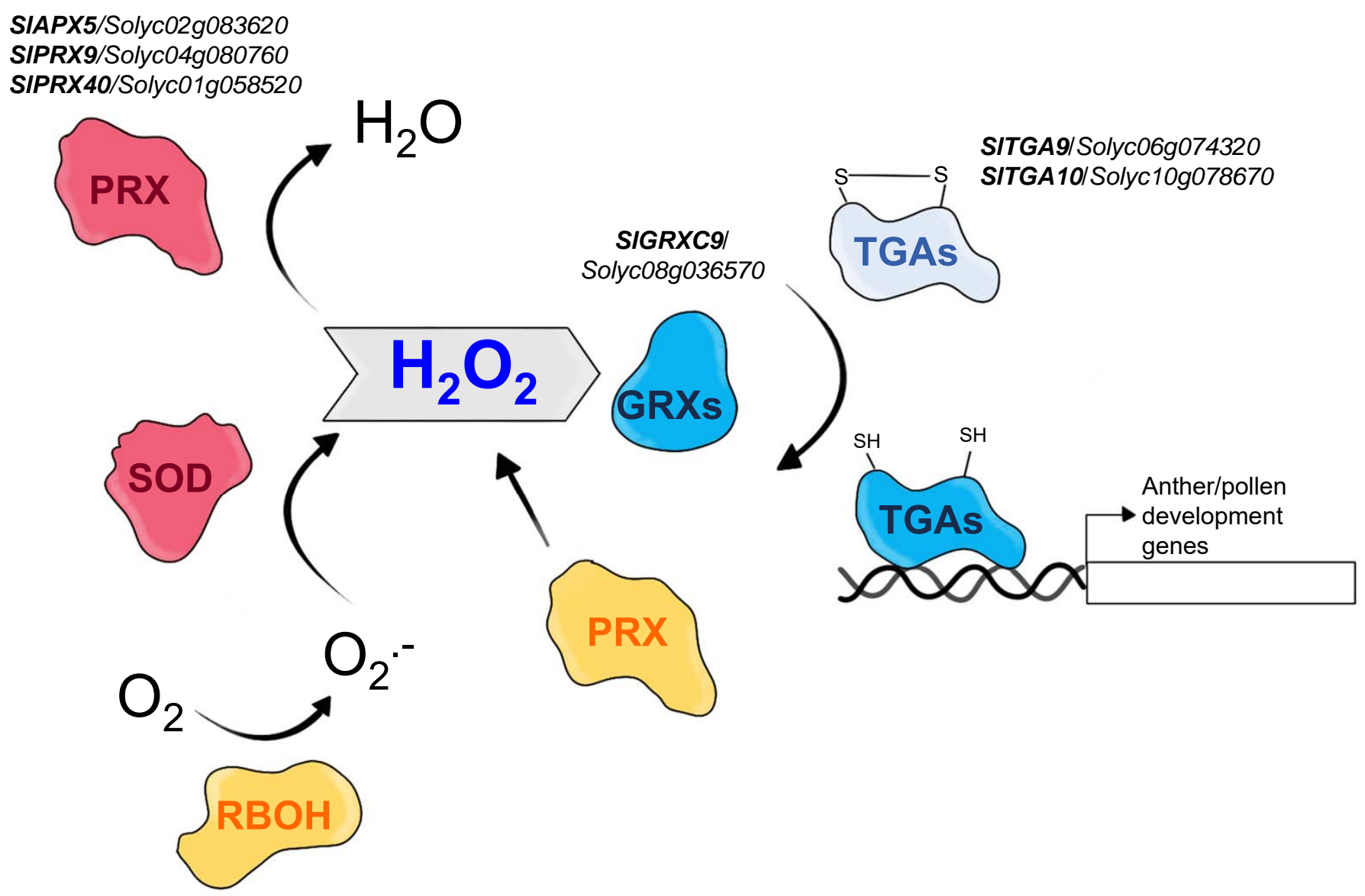

SIRbohA/Solyc01g099620 SIRbohE/Solyc06g075570 